Portland State University

PDXScholar

Spring 6-13-2018

\title{
Assessment of Observational Uncertainty in Extreme Precipitation Over the Continental United States
}

\author{
Emily Anne Slinskey \\ Portland State University
}

Follow this and additional works at: https://pdxscholar.library.pdx.edu/open_access_etds

Part of the Atmospheric Sciences Commons

Let us know how access to this document benefits you.

\section{Recommended Citation}

Slinskey, Emily Anne, "Assessment of Observational Uncertainty in Extreme Precipitation Over the Continental United States" (2018). Dissertations and Theses. Paper 4450.

https://doi.org/10.15760/etd.6334

This Thesis is brought to you for free and open access. It has been accepted for inclusion in Dissertations and Theses by an authorized administrator of PDXScholar. Please contact us if we can make this document more accessible: pdxscholar@pdx.edu. 
Assessment of Observational Uncertainty in Extreme Precipitation

over the Continental United States

by

Emily Anne Slinskey

A thesis submitted in partial fulfillment of the

requirements for the degree of

Master of Science

in

Geography

Thesis Committee:

Paul Loikith, Chair

Heejun Chang

Martin Lafrenz

Portland State University

2018 
(C) 2018 Emily Anne Slinskey 


\begin{abstract}
An extreme precipitation categorization scheme, developed to temporally and spatially visualize and track the multi-scale variability of extreme precipitation climatology, is introduced over the continental United States and used as the basis for an observational dataset intercomparison. The categorization scheme groups three-day precipitation totals exceeding $100 \mathrm{~mm}$ into five precipitation categories, or "P-Cats". To assess observational uncertainty across a range of precipitation measurement approaches, we compare in situ station data from the Global Historical Climatology Network-Daily (GHCN-D), satellite derived data from the Tropical Rainfall Measuring Mission (TRMM), gridded station data from the Parameter-elevation Regression on Independent Slopes Model (PRISM), global reanalysis from the Modern-Era Retrospective analysis for Research and Applications, version 2 (MERRA 2), and regional reanalysis from the North American Regional Reanalysis (NARR). While all datasets capture the principal spatial patterns of extreme precipitation climatology, results show considerable variability across the five-platform suite in P-Cat frequency, spatial extent, and magnitude. Higher resolution datasets, PRISM and TRMM, most closely resemble GHCN-D and capture a greater frequency of high-end totals relative to lower resolution products, NARR and MERRA-2. When all datasets are regridded to a common coarser grid, differences persist with datasets originally constructed at a high resolution maintaining the highest frequency and magnitude of P-Cats. Potential future applications of this scheme include tracking change in P-Cats over space and time, climate model evaluation, and assessment of model projected change.
\end{abstract}




\section{Acknowledgements}

I want to sincerely thank everyone who made this work possible.

I owe a great deal of gratitude to my advisor, mentor, and friend Dr. Paul Loikith. Dr.

Loikith continuously believed in me, at times more than I believed in myself, and gave me the courage to achieve more than I thought possible. His unwavering optimism, guidance, and encouragement transcended academics and fostered both my personal and professional development.

I owe a great deal of thanks to my friend and lab-mate Judah Detzer. We traveled much of this journey side by side and it was his commitment and passion for science that motivated me throughout this research.

I would also like to acknowledge the Climate Science Lab for providing their friendship and support. In addition, I would like to thank Dr. Andrew Martin for his keen eye and vast knowledge on the subject.

I further owe gratitude to my committee members, Dr. Heejun Chang and

$$
\text { Dr. Martin Lafrenz. }
$$

I would also like to thank my collaborators at the Jet Propulsion Laboratory and the members of the RCMES team. A special thanks to Alexander Goodman for aiding in the task of downloading and processing data.

I am deeply grateful for the support of my family who taught me to work hard and never give up. Finally, I would especially like to thank Zachary Kane-Seitz for his love and patience, without which this work would not have been possible. 
This work was carried out, in part, at the Jet Propulsion Laboratory, California Institute of Technology and at Portland State University, under a contract from National Aeronautics and Space Administration (NASA). Support for this project was provided by the NASA Indicators for the National Climate Assessment (NCA) Program. 


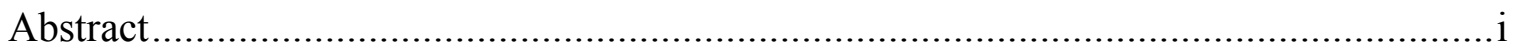

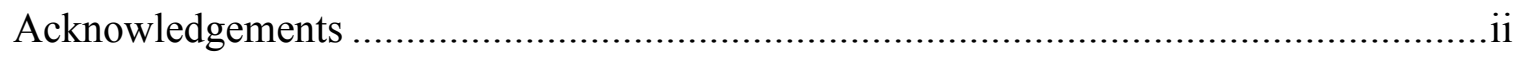

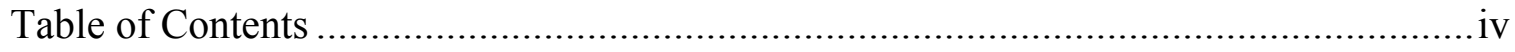

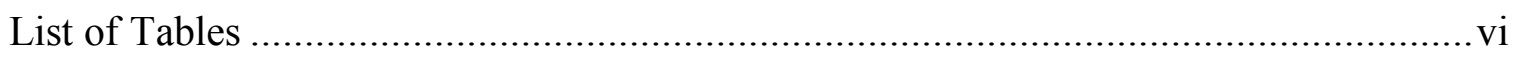

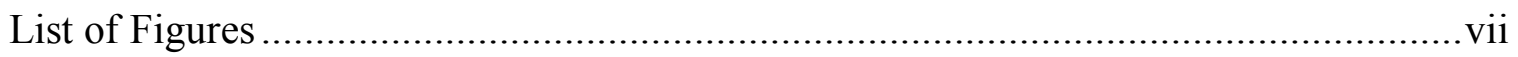

Chapter 1: Introduction and Review of Relevant Literature .............................. 1

1.1: Motivation and Research Objectives .................................................... 1

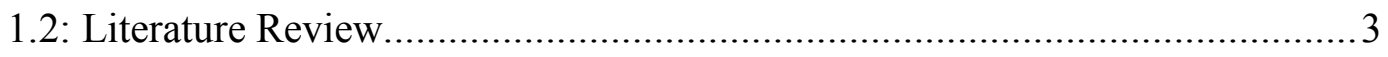

1.2.1: Observed Trends in Extreme Precipitation across the CONUS ........ 3

1.2.2: Existing Monitoring Efforts ................................................ 4

1.2.3: Measuring and Constraining Uncertainty ................................5

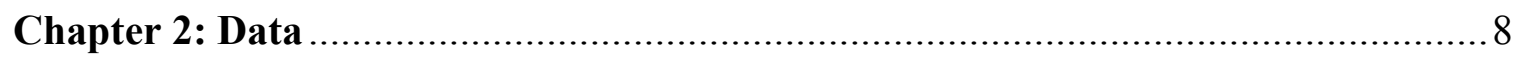

2.1: Tropical Rainfall Measuring Mission (TRMM) 3B42V7 .......................... 8

2.2: Global Precipitation Measuring Mission (GPM) ................................... 8

2.3: Parameter-elevation Regressions on Independent Slopes Model (PRISM)....9

2.4: Modern-Era Retrospective analysis for Research and Applications, version 2 (MERRA-2) ...................................................................................... 9

2.5: North American Regional Reanalysis (NARR) .................................... 10

2.6: Global Historical Climatology Network (GHCN)................................ 10

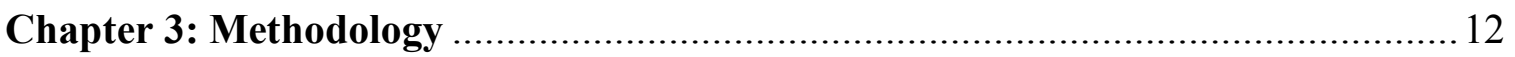


3.1: Extreme Precipitation Categorization Scheme

3.2: Dataset Intercomparison.

Chapter 4: Results and Discussion.

4.1: Annual Precipitation Climatology ..................................................... 15

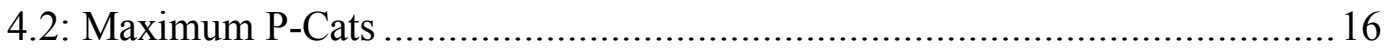

4.3: Mean Frequency of P-Cat Occurrence....................................................22

4.4: Annual P-Cat Occurrence.................................................................. 26

4.5: Global Precipitation Measurement (GPM) Intercomparison .....................228

Chapter 5: Summary, Conclusions, and Implications for Future Work................... 30

5.1: Summary and Conclusions …................................................... 30

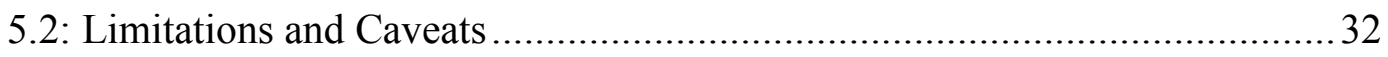

5.3: Broader Implications and Future Direction......................................... 33

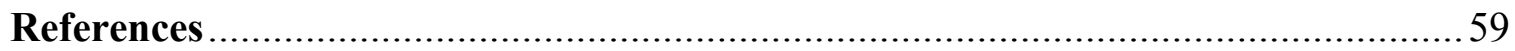




\section{List of Tables}

Table 1. Datasets used in the intercomparison and the associated specifications.............34

Table 2. Dataset's coefficient of variation values for each P-Cat's annual frequency

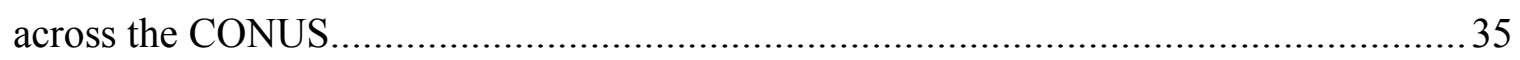

Table 3. Same as in Table 2 except for SON and only over the Southeast sub-region..... 36

Table 4. Same as in Table 2 except for DJF and only over the Northwest sub-region ..... 37 


\section{List of Figures}

Figure 1. P-Cat thresholds and associated colors used in subsequent figures 38

Figure 2. The seven NCA sub-regions and the associated abbreviations 39

Figure 3. Average annual precipitation over the period of 1998-2015. Results are for (a) GHCN-D, (b) PRISM, (c) TRMM, (d) NARR, and (e) MERRA-2 40

Figure 4. Maximum observed P-Cat at each grid point over the 1998-2015 period. (a-d) Maximum P-Cats on native grid, (e-h) maximum P-Cats on common MERRA-2 grid. Regridded datasets are indicated with an asterisk. Color scale is as in Figure 1. Un-shaded grid cells indicate that no P-Cat has occurred during the data record 41

Figure 5. Same as in Figure 4 except for SON

Figure 6. Same as in Figure 4 except for DJF.

Figure 7. Taylor diagrams quantifying the spatial correspondence of the maximum observed P-Cats for TRMM, MERRA-2, and NARR relative to PRISM. Results are for (a) the CONUS annually and seasonally and relevant NCA sub-regions (b) annually and seasonally for (c) September, October, November and (d) December, January, February. Each dataset is labeled by a symbol with each season and sub-region assigned a color as defined in the legends in the top two panels. The $\mathrm{x}$ and $\mathrm{y}$ axes correspond to the standard deviation ratio between the indicated dataset and PRISM. The radial axis is the pattern correlation, and the distance between the symbol and the PRISM location is proportional 
to the centered root mean squared difference between the spatial field of the maximum PCats of the indicated dataset and PRISM, normalized by the spatial standard deviation of the PRISM field. 45

Figure 8. (a-e) Mean annual frequency of P-Cat occurrence over the 1998-2015 record, (f-h) the frequency bias is recorded as the difference between the mean annual frequency of P-Cat occurrence in the indicated dataset and PRISM. Frequencies are recorded as the number of P-Cats per year. Regridded datasets are indicated with an asterisk

Figure 9. Same as in Figure 8 except for SON

Figure 10. Same as in Figure 8 except for DJF .50

Figure 11. Same as in Figure 7 except for the mean frequency of P-Cat occurrence patterns. 51

Figure 12. Annual frequency of observed P-Cats over the 1998-2015 period. (a-d) Annual frequency of P-Cats on native grid, (e-h) annual frequency of P-Cats on common grid. Regridded datasets are indicated with an asterisk. Gray bars represent P-Cat 1, green PCat 2, yellow P-Cat 3, orange P-Cat 4, and red P-Cat 5 as in the legend in Figure 1. Results are plotted on a log scale

Figure 13. Same as in Figure 12 except for SON and only over the Southeast sub-region .54 
Figure 14. Same as in Figure 12 except for DJF and only over the Northwest sub-region

Figure 15. Maximum observed P-Cats during April 2014-December 2015, the TRMM/GPM overlap period. Results are for (a) GHCN-D, (b) GPM, (c) TRMM, (d) P-

Cat frequency per grid cell/station observed over the time record 58 


\section{Chapter 1: Introduction and Review of Relevant Literature}

\section{1: Motivation and Research Objectives}

Extreme precipitation is associated with a multitude of societal and environmental impacts across the United States (US). Often accompanying severe weather events, including hurricanes, snowstorms, and atmospheric river (AR) landfalls, these events pose threat to property, agriculture, infrastructure, and human life while also playing a key role in the water budget (Kunkel et al. 2013). According to the 2017 National Climate Assessment (NCA) Climate Science Special Report, climate change is projected to alter the frequency, severity, and seasonality of extreme precipitation across the US (Easterling et al. 2017). Climate change mitigation policies and adaption initiatives are greatly influenced by societal vulnerabilities to climate impacts like those associated with extreme precipitation. Therefore, a comprehensive understanding and intuitive way to track and project change across space and time, at impacts-relevant scales, is critical in order to best prepare for and adapt to change.

Increasing trends in extreme precipitation events have been observed over the contiguous United States (CONUS) using a range of detection and analysis methods (Karl et al. 1995; Karl and Knight 1998; Kunkel et al. 1999, 2007, 2012, 2013; Alexander et al. 2006; Easterling et al. 2017). Climate model projections of future change in global precipitation generally follow the Clausius-Clapeyron relationship, projecting the atmosphere's water holding capacity to increase exponentially with temperature at roughly 7\% per degree warming (Allen and Ingram 2002; Trenberth et al. 2003; Pall et al. 2007). Consistent with these expectations, a number of recent studies have attributed 
anthropogenic climatic warming to increases in the severity of recent extreme precipitation events over the US, including the Colorado floods of 2013 (Pall et al. 2013; Gochis et al. 2015) and the 2016 Louisiana event (Wang, Zhao, and Gillies 2016). However, in most cases the sign and magnitude of changes in extreme precipitation are not immediately apparent from observational analysis at regional scales. With anthropogenic climate change projected to alter trends in precipitation intensity across portions of the CONUS (Min et al. 2011, 2013; Zhang et al. 2013; Easterling et al. 2017), a spatial understanding and intuitive means of monitoring extreme precipitation over time is imperative.

Toward this end, we present an extreme precipitation categorization scheme, motivated by a need for an intuitive pointwise climate indicator for extreme precipitation at scales relevant to societal and environmental impacts. The approach, which assigns extreme precipitation categories, based on 3-day storm totals, at each data point (i.e. grid cell or gauge station), is designed to be intuitive and easily interpretable, informing on variability and change at local, regional, and global scales. The usefulness and utility of this monitoring scheme is further demonstrated through its application as the basis for a dataset intercomparison to assess observational uncertainty across a wide range of historical precipitation measurement approaches. This indicator is intended to serve the scientific community by providing an intuitive metric for assessing observed and projected changes in extreme precipitation climatology, while also being useful and interpretable to a broad range of user communities and stakeholders. The ability of the climate indicator to provide regional information suits stakeholders at the local to state 
level, within both private and public sectors, including agricultural and construction interests, local and state governments, as well as urban planners. As an intuitive longterm monitoring tool, it will allow users to identify if their region has been experiencing changes in the frequency and intensity of precipitation extremes.

\section{2: Literature Review}

\subsection{1: Observed Trends in Extreme Precipitation across the CONUS}

Extreme precipitation results from a range of mechanisms across the CONUS with strong seasonality and interannual variability, generating impacts with wide regional variation. For example, a majority of the extreme wintertime precipitation across the western US results from landfalling atmospheric rivers (AR) (Neiman et al. 2008a, 2008b; Ralph and Dettinger 2011, 2012). ARs cause devastating environmental impacts, including flooding, landslides, and debris flows (Ralph et al. 2006; Dettinger 2011). However, ARs also yield important beneficial outcomes providing 30\%-50\% of the regions annual precipitation in addition to valuable snowfall at higher elevations (Guan et al. 2010, 2013; Dettinger et al 2011). Another example are the warm season extreme rainfall events over the southeastern US driven by landfalling tropical cyclones (TC) (Knight and Davis 2009; Knutson et al. 2010; Kunkel et al. 2010). The geography and topography of this region make it more prone to long duration river flooding compared to the West. While not as extreme, other regions, such as the Great Plains in the spring and the Northeast in the summer, experience heavy and impactful storms from strong convective systems resulting in increased flood frequency and severity. 
Numerous studies have identified increasing trends in the frequency and intensity of extreme precipitation regionally across the CONUS (Karl et al. 1995; Karl and Knight 1998; Kunkel et al. 1999, 2013; Janssen et al. 2014, 2016; Easterling et al. 2017) as well as globally (Lehmann et al. 2015; Donat et al. 2016). The most notable upward trends have been observed in the Northeast and Midwest (Kunkel et al. 2013; Janssen et al. 2014; Easterling et al. 2017). Focusing on the Northeast, changes have been observed and quantified using extremes indices highlighting the interaction between atmospheric modes of variability and extreme precipitation (Griffiths and Bradley 2007; Brown et al. 2010). Increases in the contribution of specific meteorological mechanisms have also been observed, including TCs along the southeastern Atlantic coastal states (Knight and Davis 2009; Knutson et al. 2010; Kunkel et al. 2010) and ARs across the West (Dettinger et al. 2011; Gao et al. 2015; Warner et al. 2015). Furthermore, understanding observed and projected changes in the frequency and intensity of precipitation extremes and the associated dynamics is still an area of active research (e.g. Pratt and Nelson 2013; Gao et al. 2015; Behrangi et al. 2016; Mahoney et al. 2016; Lamjiri et al. 2017). Moreover, monitoring changes in precipitation extremes with regional specificity so as to capture the radically different meteorological realization of extremes is imperative for assessing projected change.

\subsection{2: Existing Monitoring Efforts}

Several indices for studying extreme precipitation climatology and change have been developed and applied to a diverse set of datasets using a range of methods (Zhang et al. 2011 and references therein). Frich et al. (2002), and further built upon by Alexander et 
al. (2006), introduced a set of extremes indices known as the Expert Team on Climate Change Detection and Indices, developed as part of the World Climate Research Programme Project on Climate Variability and Predictability ${ }^{1}$. Trends in these indices have been updated and developed into a set of extremes indices using coarsely gridded station-based observations. These indices were designed to address a broad range of global climate information needs ranging from the frequency of precipitation threshold exceedances to the maximum length of wet spells.

Specific to the US, precipitation extremes have been monitored using the US Climate Extremes Index (Gleason et al. 2008), available through the National Centers for Environmental Information (NCEI) ${ }^{2}$. The US Environmental Protection Agency has also compiled a list of climate indicators, including one for annual heavy precipitation, which measures the percent of land over the CONUS that experiences heavy precipitation (US

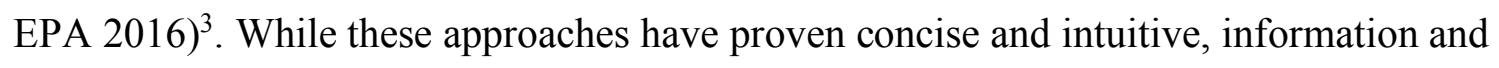
monitoring at scales relevant to stakeholders is essential for informing environmental planning and decision-making. It is important that changes in the frequency of highly regionalized phenomena associated with extreme precipitation are recognizable and monitored at regionally relevant scales.

\subsection{3: Measuring and Constraining Uncertainty}

The ability to understand and, where possible, constrain observational uncertainty is fundamental when visualizing and tracking extreme precipitation across space and time.

\footnotetext{
${ }^{1} \mathrm{https} / / / \mathrm{www} . c$ limdex.org/indices.html

2 http://www.ncdc.noaa.gov/extremes/cei

3 https://www.epa.gov/climate-indicators/climate-change-indicators-heavy-precipitation
} 
Furthermore, the approach used to estimate precipitation observations will likely play a substantial role in the level and geography of uncertainty. For example, remotely sensed precipitation measurement (TRMM and follow on GPM in this study) carries benefits over other methods in that satellite retrievals are spatially seamless regardless of in situ gauge density or quality. However, TRMM and GPM also have inherent biases (Chen et al. 2013; Tan, Petersen, Tokay 2016), such as deficiencies at detecting snow at higher elevations (Behrangi et al. 2014), which should be quantified relative to other state-ofthe-art precipitation measurement products. Differences across products may stem from a variety of sources, including instrument sensitivities and retrieval algorithm biases for remote sensing (Ebert et al. 2007; Turk et al. 2008; Behrangi et al. 2014), analysis and modeling errors for reanalysis (Bukovsky and Karoly 2007; Hanson et al. 2007; Bosilovich et al. 2008; Reichle et al. 2017), spatial interpolation in gridded in situ products (Daly 2006), or spatial resolution (Herold et al. 2017). In situ station data is commonly accepted as a primary source for climatic studies and often used as a reference relative to other products. However, station observations are spatially heterogeneous and may be temporally inconsistent, creating observational gaps (Kidd et al. 2017). Furthermore, the ability to detect, analyze, and understand changes related to extreme precipitation is heavily dependent on the reliability of observations.

A number of precipitation climatology and dataset intercomparison studies have been conducted from global to regional scales (e.g. Adler et al. 2001; Guirguis and Avissar 2008 respectively). Contractor et al. (2015) found large regional uncertainties in extreme precipitation magnitude, across a range of gridded products over Australia. Trends in 
precipitation extremes have also been assessed and determined to be spatially heterogeneous and described as both positive and negative depending on the dataset being used (Yin et al. 2015). Additionally, the high spatial and temporal variability characterizing precipitation extremes has produced exceedingly low agreement among a range of global precipitation measurement products (Donat et al. 2013). The substantial evidence of uncertainty across precipitation measurement products can therefore lower confidence in analysis results if this uncertainty is not carefully considered. Here we perform a comprehensive dataset intercomparison to provide additional insight into observational uncertainty as it pertains to the categorization scheme, assessing differences across a range of measurement approaches spanning in situ, gridded in situ, and global and regional reanalysis. 


\section{Chapter 2: Data}

\section{1: Tropical Rainfall Measuring Mission (TRMM) 3B42V7}

Satellite-derived precipitation data are from NASA's TRMM Multi-satellite Precipitation Analysis (TMPA) 3B42V7 product (Huffman et al. 2007; Huffman and Bolvin 2015). Prior to its decommissioning in 2015, TRMM was NASA's flagship precipitation measurement product (Liu et al. 2012). The TRMM 3B42V7 is provided with a 3-hourly temporal and $0.25^{\circ}$ latitude/longitude spatial resolution, extending globally from $50^{\circ} \mathrm{N}$ to $50^{\circ} \mathrm{S}$ latitude spanning the years $1998-2015$. TRMM measurements are produced using microwave-calibrated infrared (IR) estimates from multiple geo-stationary earth-orbiting and low-earth orbiting satellites (Huffman et al. 2007). The final precipitation estimates contain microwave-derived measurements and calibrated thermal IR-derived estimates. The spatial domain accounts for the tendency of microwave and IR estimates to lose skill at higher latitudes (Huffman et al. 2010). The 3B42V7 product incorporates monthly in situ gauge observations from the Global Precipitation Climatology Center and the Climate Assessment and Monitoring System for bias adjustment.

\section{2: Global Precipitation Measuring Mission (GPM)}

The GPM Mission-Integrated Multi-Satellite Retrievals (IMERG) product was developed as an extension of TRMM 3B42V7 after it's decommission. GPM data are provided at $0.1^{\circ}$ latitude/longitude resolution every half hour between $60^{\circ} \mathrm{N}$ and $60^{\circ} \mathrm{S}$ latitude (Hou et al. 2014; Liu 2016). The GPM core observatory presents an increased orbiting inclination over TRMM, from $35^{\circ}$ to $65^{\circ}$ respectively, rendering more extensive 
latitudinal coverage (Huffman et al. 2017). Additionally, more advanced instrumentation capable of capturing multiple phases of precipitation is possible through the addition of a higher frequency radar offering an improved sensitivity to light precipitation as well as to snow and ice. IMERG integrates algorithms from TMPA, the Climate Prediction Center morphing technique, and Precipitation Estimation from Remotely Sensed Information using Artificial Neural Networks. As of the writing of the paper, IMERG extends from April 2014 to the present, but will be retro-processed to overlap the TRMM era. GPM IMERG and TRMM 3B42V7 are freely available via the GES DISC.

\section{3: Parameter-elevation Regressions on Independent Slopes Model (PRISM)}

PRISM is a climate analysis system that uses point data and a digital elevation model (DEM) to generate gridded precipitation data (Daly et al. 1994). We utilize the daily PRISM product, offered on a $0.04^{\circ}$ latitude/longitude grid over the CONUS. The PRISM technique attempts to account for topographic effects using the linear regression between gauge measurements and the elevation of the gauge taken from a DEM. The gauge measurements used for interpolation are supplied by various sources including the US National Weather Service Cooperative Observer Network and the Natural Resources Conservation Service daily snow pack telemetry gauges. The PRISM product is freely available from Oregon State University's PRISM Climate Group portal.

\section{4: Modern-Era Retrospective analysis for Research and Applications, version 2 (MERRA-2)}

The MERRA-2 atmospheric reanalysis product provides 3-hourly precipitation estimates generated on a $0.625^{\circ} \times 0.5^{\circ}$ latitude-longitude grid. MERRA-2 is the latest 
multi-year reanalysis product produced by NASA's Global Modeling and Assimilation

Office using the Goddard Earth Observing System version 5 (Molod et al. 2015; Gelaro et al. 2017; Reichle et al. 2017). This product corrects model generated precipitation estimates with observations, showing marked improvements upon its predecessor MERRA (Rienecker et al. 2011; Reichle et al. 2017). The method for merging observed precipitation into MERRA-2 assimilates aerosols and integrates MERRA-Land reanalysis for correction (Reichle et al. 2017). Estimates are further merged with precipitation generated by the MERRA-2 atmospheric general circulation model weighted according to latitude. MERRA-2 is freely available via the GES DISC.

\section{5: North American Regional Reanalysis (NARR)}

NARR is based on the regional Eta Model and uses a 3D variation data assimilation system initialized from lateral boundary conditions provided by the National Centers for Environmental Prediction (Mesinger et al. 2006). It is freely available through the National Oceanic and Atmospheric Administration's Earth System Research Laboratory. This product is provided at a 3 -hourly temporal resolution and a $32 \mathrm{~km}$ spatial resolution (Lin et al 1999). Precipitation gauge observations are used to adjust atmospheric moisture and energy field estimates to improve model-derived precipitation fields.

\section{6: Global Historical Climatology Network (GHCN)}

In situ daily observations are from the NCEI Global Historical Climatology NetworkDaily (GHCN-D) product (Menne et al. 2012). This dataset contains comprehensive in situ climatic data that has undergone extensive quality control procedures to limit 
internal, spatial, and temporal inconsistencies (Durree et al. 2010). For this study, only gauges reporting at least $90 \%$ of days over the period of 1998-2015 are included. The data are frequently updated and can be obtained freely via the web from the NCEI. 


\section{Chapter 3: Methodology}

\section{1: Extreme Precipitation Categorization Scheme}

Extreme precipitation three-day totals are grouped into five precipitation categories, or "P-Cats", according to their overall accumulated three-day storm total, analogous to the widely recognized Saffir-Simpson hurricane intensity index. P-Cats are defined as follows: three-day totals between 100 and $199 \mathrm{~mm}$ are assigned to P-Cat 1, between 200 and $299 \mathrm{~mm}$ to P-Cat 2, between 300 and $399 \mathrm{~mm}$ to P-Cat 3, between 400 and $499 \mathrm{~mm}$ to P-Cat 4, and greater than $500 \mathrm{~mm}$ to P-Cat 5 (Figure 1). Three-day storm totals are defined as the sum of precipitation for that day and the two preceding days such that if a P-Cat 4 is recorded on January $4^{\text {th }}$ at a given location, the precipitation accumulated over January $2^{\text {nd }}, 3^{\text {rd }}$, and $4^{\text {th }}$ totaled between 400 and $499 \mathrm{~mm}$. This window is then moved forward by one day each time step so that the three-day total for each day includes the sum of that day and the previous two. The use of fixed thresholds here is intuitive and allows for direct comparisons across regions, unlike percentile-based thresholds calculated at each grid cell/station. The P-Cat approach is similar to the R-Cat approach introduced by Ralph and Dettinger (2012) and used operationally by the Scripps Institute of Oceanography Center for Western Weather and Water Extremes ${ }^{4}$. Our P-Cats 2-5 are the same as R-Cats 1-4, however we add an additional lower category. Multi-day totals have been suggested as the most relevant to regional hydrologic impacts including flooding and landslides (Ralph and Dettinger 2012). Furthermore, Ralph and Dettinger (2012) indicate that the three-day window provides the best representation of major

\footnotetext{
${ }^{4}$ http://cirrus.ucsd.edu/ pierce/rcatalert/
} 
storms, with two-day totals missing storms and four-day periods revealing negligible differences to three-day periods.

\section{2: Dataset Intercomparison}

To assess the effect of observational uncertainty on using the P-Cat approach to describe and monitor extreme precipitation three-day totals through time and space, we compare the magnitude and frequency of P-Cats across a five-dataset suite. Magnitude is assessed by comparing the maximum observed P-Cat at each data point, while frequency is defined as the average number of P-Cats per year or season. Dataset comparisons are performed and summarized over the CONUS and over the seven multi-state defined NCA regions (Figure 2; Easterling et al. 2017). All comparison analyses are performed at the annual and standard meteorological seasonal scales with winter defined as December, January, February (DJF), spring as March, April, May (MAM), summer as June, July, August (JJA), and fall as September, October, November (SON). Comparison is performed over the period 1998-2015, which is the period of maximum overlap across all the datasets. Additionally, GPM is compared with TRMM for the years of overlap (20142015).

Results for all the datasets are presented both on their native grid and a common grid for comparison and to assess the effect of spatial scale on P-Cat frequency and magnitude. Gridded datasets were regridded, prior to assigning P-Cats, to a common $0.625^{\circ} \times 0.5^{\circ}$ grid over the CONUS. This resolution matches that of the coarsest resolution product included in the study, MERRA-2. To rescale each gridded product, a linear method of spatial regridding was employed based on Delaunay triangulation (Lee 
and Schrachter 1980; Kang et al. 1997; Liu et al. 2008). The spatial correspondence between the patterns of the regridded results were quantitatively assessed and summarized using Taylor diagrams, in terms of the centered root mean squared difference (CRMSD), standard deviation, and correlation coefficient. To construct a Taylor diagram, one dataset must be chosen as the reference to measure dataset similarities and differences against. In all Taylor diagrams here PRISM is used as the reference dataset, chosen because it is the only gridded dataset based primarily on gauge data; however, we do not intend to argue that PRISM is truth and immune from bias. 


\section{Chapter 4: Results and Discussion}

In this chapter we describe the application of the P-Cat scheme for informing on extreme precipitation climatology across the suite of observational datasets and discuss the similarities, differences, and apparent limitations of each product. These results demonstrate the utility of the P-Cat scheme while also showing that results can vary considerably depending on which dataset the P-Cat scheme is applied to.

\section{1: Annual Precipitation Climatology}

Mean annual precipitation is shown in Figure 3 for the five datasets on their native resolutions to assess similarities and differences in mean precipitation before evaluating extremes in subsequent figures. All datasets show similar general regional climatology patterns with the highest mean precipitation over the mountains of northern California, Oregon, and Washington and over the Southeast. Using GHCN-D as a reference (Figure 3a), considerable differences across the data suite emerge. First order differences relate to the representation of the effect of topography on precipitation, with the high-resolution PRISM (Figure 3b) best resembling GHCN-D over the mountainous West and the lowest resolution MERRA-2 (Figure 3e) showing the least detail. Spatial resolution is not the only factor contributing to differences in annual precipitation amount. For example, TRMM has a notable dry bias relative to GHCN-D across the mountains of the Northwest despite its relatively high spatial resolution (Figure 3c), likely due to limitations in the ability of TRMM to measure snowfall (Bharti and Singh 2015). NARR (Figure 3d) has a broad dry bias over much of the Southeast compared with GHCN-D and the other three datasets. MERRA-2 is too coarse to resolve most details of individual mountain ranges; 
however, it does show some qualitative similarities with GHCN-D over the coastal Northwest and northern Rocky Mountains.

\section{2: Maximum P-Cats}

Here we present a comparison of the maximum recorded P-Cats across the CONUS for all datasets. Results are presented for the full year (Figure 4), for DJF (Figure 5), and for SON (Figure 6). Fall and winter are chosen for seasonal analysis because they are concurrent with the most widespread occurrence of extreme precipitation totals, spanning two primary meteorological mechanisms: landfalling atmospheric rivers in the West in both seasons (Neiman et al. 2008a, 2008b; Ralph and Dettinger 2011, 2012) and landfalling tropical systems in the Southeast in the fall (Knight and Davis 2009; Knutson et al. 2010; Kunkel et al. 2010). Results are summarized across seasons and sub-regions using Taylor diagrams in Figure 7.

Figure 4 shows the maximum P-Cat observed over the entire 18-year record for each data point. The spatial distribution of maximum observed P-Cats in GHCN-D (Figure 4a, analogous to Figure 3 from Ralph and Dettinger 2012) generally resembles the precipitation climatology in Figure 3, with the highest P-Cats coinciding with the highest annual rainfall. This is supported in the West by the prevalence of high-end P-Cats across the coastal mountain ranges, the Sierra Nevada and Cascade ranges, and the Transverse Ranges of southern California. High-end P-Cats are also more prevalent in the Southeast stretching from Texas eastward to the Carolinas. The maximum P-Cats recorded during this period are generally much lower across the Great Plains, the desert Southwest, and the interior western rain shadows. 
Using the GHCN-D station data as a qualitative reference, all datasets capture the general pattern of relatively high P-Cats in the western mountains and Southeast and low P-Cats over the Great Plains and Southwest. However, considerable differences are apparent in extent and magnitude. For example, PRISM shows the most widespread PCat 4 and $5 \mathrm{~s}$, consistent with expectations from it having the finest grid resolution. PRISM also most closely resembles the GHCN-D station data, in a qualitative sense, as compared with the other datasets and is best able to resolve topographic details. PRISM shows a multitude of high-end P-Cats over the Southeast, which the other datasets do not capture, suggesting localized convective precipitation, which is best captured at high resolution, is the primary culprit. The reduced magnitude of P-Cats in this region in the coarser datasets may result primarily from spatially smoothing out the localized heavy rainfall. Supporting the relationship between resolution and high-end P-Cats, TRMM (Figure 4c) also captures a greater occurrence of high-end extremes compared to lower spatial resolution datasets, NARR and MERRA-2 (Figures 4d,e).

While regridding reduces some of the P-Cat magnitudes through spatial smoothing, some differences persist after the datasets are rescaled to a common grid (right column of Figure 4; i.e. regridded to MERRA-2 resolution). In the case that high resolution is necessary for capturing processes leading to extreme precipitation totals, such as localized convection, then it is possible that a high-resolution dataset will maintain some high-end P-Cats compared with the coarser products. Potentially illustrative of this effect, PRISM maintains a relatively high number of P-Cat $3-5 \mathrm{~s}$ after regridding (Figure $4 \mathrm{f}$ ). The same effect is apparent for TRMM over the Southeast and Northwest. In addition to 
spatial resolution, other factors may also be important in determining the level of agreement after regridding, including differences in the ability of the analysis products to accurately capture land-atmosphere interaction or potential bias and overestimation in PRISM (Mesinger et al 2006; Bharti and Singh 2015; Molod et al. 2015).

The Taylor diagrams in Figure 7a,b summarize the dataset correspondence for the CONUS and NCA sub-regions respectively. All datasets show a lower spatial standard deviation relative to PRISM with TRMM generally falling closest to PRISM across all seasons over the CONUS. However, TRMM has a greater spread in pattern correlation resulting in larger CRMSD values compared with NARR and MERRA-2, especially for DJF and MAM. Both NARR and MERRA-2 cluster closely at the CONUS scale across the seasonal cycle. More spread is apparent at the sub-region scale (Figure 7b) with all datasets systematically showing smaller spatial variance than PRISM. The largest outliers are for the Great Plains North region, where few P-Cats occur, making the sample size small for comparison. For most sub-regions and most datasets, the spread in agreement is largely manifested in the standard deviation ratio, with common pattern correlations between 0.6 and 0.8 .

In the same format as Figure 4, the maximum recorded P-Cats for SON are shown in Figure 5. The highest observed P-Cats captured by GHCN-D (Figure 5a) are over the Pacific Northwest, central Texas, and the Gulf and Atlantic Coasts of the Southeast. PCat 1 and 2s are common throughout the higher elevations of the West and across the Midwest through the Northeast. Several examples of Southwest to Northeast oriented bands of P-Cat $2 \mathrm{~s}$ as the highest recorded three-day total are apparent in the central US. 
For example, one band extends from northern Illinois to southeastern Michigan. These coherent bands are indicative of southwest to northeast propagating storm systems, likely producing heavy rainfall over an extended geography and providing a useful baseline for comparing the details of the other datasets. In many cases, very high-end P-Cats can readily be traced to the contributing storm. For example, the high values over eastern North Carolina are the result of Hurricane Floyd that made landfall in September of 1999. The similarities between Figures 5 and 4 over the Southeast make it clear that most of the highest recorded P-Cats in this region occur during SON.

Consistent with previous findings, PRISM captures the greatest magnitude and spatial extent of high-end P-Cats (Figure 5b), sharing the most similarities with the GHCN-D results, including the southwest to northeast oriented bands of P-Cat 2s across the Midwest. PRISM also shows high-end P-Cats in the mountainous regions of Washington and Northern Oregon and across the coastal Southeast in the same places as GHCN-D. These features are generally captured in the other datasets, however with lower magnitudes. In some cases, regional scale details are not similar across the suite especially in the case of the high-end P-Cats over the Southeast where MERRA-2 and NARR show varying degrees of dissimilarities with the other datasets. As in Figures 3 and 4, there is a close relationship between spatial resolution and P-Cat magnitude, however even considering a systematic resolution related bias, some fundamental differences persist.

After spatial regridding, PRISM and TRMM maintain many high-end P-Cats over Washington and North Carolina (Figure 5f,g). MERRA-2 and NARR continue to show 
systematically lower P-Cat magnitudes relative to the regridded PRISM and TRMM, providing further evidence of factors other than resolution being influential on dataset agreement (Figures 5e,h). In Figure 7c dataset spread is large, especially across the variance ratio, with TRMM showing the most similar variance to PRISM, while MERRA-2 often exhibits the highest variation of correlation between 0.5 and 0.9 . Note that we omit results for Great Plains North and Southwest because of the very small number of grid cells with P-Cats in these regions.

In DJF (Figure 6) GHCN-D shows the most extreme precipitation three-day totals occurring along the western mountains stretching from northern Washington to southern California and across the southern Midwest and Southeast (Figure 6a). The intense precipitation from these North Pacific extratropical cyclones is maximized by the orographic enhancement of landfalling ARs (e.g. Neiman et al. 2008a, 2008b; Guan et al. 2010, 2013; Ralph and Dettinger 2012). Across the eastern half of the CONUS, high-end P-Cats are the result of strong midlatitude cyclones that strengthen along the strong temperature gradients formed by southward excursions of Arctic air masses. Evidence of these sometimes intense eastward and northeastward propagating storms is suggested by the southwest to northeast bands of P-Cat 2s throughout the eastern and southeastern portions of the CONUS.

In agreement with GHCN-D, PRISM shows many of the high-end P-Cats that occur across the West (Figure 6b). TRMM's limitations at capturing snowfall are apparent with considerable under-estimation of the magnitude of P-Cats occurring along the Sierra Nevada and Cascades (Figure 6c). These results are consistent with Behrangi et al. 
(2014), emphasizing the inherent challenges associated with measuring precipitation in remote regions, where station data are sparse, orography and fine scale processes are key, and precipitation type limits the utility of TRMM retrievals. Substantial differences in the magnitude of P-Cats captured by NARR and MERRA-2 (Figures 6d,e) suggest that grid resolution may inhibit the ability of a dataset to capture the impact of localized phenomena, although both datasets capture the broad patterns across the West and Southeast.

While regridding reduces the overall magnitude of P-Cat intensity in PRISM and TRMM, both datasets continue to show more P-Cat 3-5s. Over the Southeast, resolution is not as important at capturing high-end P-Cats, which is consistent with the typical synoptic-scale storms that result in extreme precipitation here in winter. The Taylor diagram in Figure $7 \mathrm{~d}$ shows that TRMM exhibits a higher variance relative to PRISM over the Southeast, with all other datasets and sub-regions showing roughly half the spatial variance of PRISM and pattern correlation coefficients between 0.5 and 0.8 . Note that only the Southwest, Northwest, and Southeast are included in Figure $7 \mathrm{~d}$ due to the small number of grid cells showing P-Cats in the other sub-regions.

\section{3: Mean Frequency of P-Cat Occurrence}

As for comparison of P-Cat magnitude in the above section, P-Cat frequency, computed as the number of P-Cats per year/season, is compared across the entire year (Figure 8), for SON (Figure 9), and for DJF (Figure 10). Differences across the data suite are also presented as biases, with reference to PRISM, and with results summarized in the Taylor diagrams in Figure 11. The distribution of the mean frequency of P-Cats in 
GHCN-D (Figure 8a) follows a similar spatial pattern to the occurrence of the highest magnitude P-Cats in Figure 4, namely that the stations that tend to have the highest maximum P-Cats also have the highest annual frequency. These areas include the Southeast and the mountains of the Pacific Northwest and California where annual P-Cat frequency exceeds 100 . In contrast, a large swath of the eastern half of the domain experiences between 20 and $50 \mathrm{P}$-Cats annually, while P-Cats are infrequent across the High Plains and all but the highest elevations of the inland West. In some places, P-Cats may not necessarily be "extreme" relative to local climatology. For example, over the mountains of California nearly 100 days out of every year are part of a P-Cat. Therefore, it is important to note that here we invoke extreme as a descriptor for P-Cats relative to CONUS-wide precipitation climatology. When frequencies are assessed for low-end and high-end P-Cats separately, it is evident that P-Cat 1 and 2 s make up the vast majority of P-Cats/year with some areas of the West and Southeast recording as many as 2 high-end P-Cats/year (not shown).

Compared with GHCN-D, all datasets capture the principal spatial patterns of annual P-Cat frequency. Qualitatively, PRISM (Figure 8e) most closely resembles GHCN-D, even capturing many of the small-scale features in areas of complex terrain. The spatial distribution and frequency magnitudes are quite similar across the eastern half of the CONUS between GHCN-D and PRISM, with PRISM capturing the area of relatively high P-Cat frequencies centered on southern Louisiana. TRMM (Figure 8b) also resembles GHCN-D in general pattern agreement, however the frequency bias map (Figure 8f) shows higher frequencies across the eastern half of the CONUS and over the 
valleys of the coastal Northwest with lower frequencies across the western mountains, compared with PRISM. NARR and MERRA-2 both share similarities, with systematically lower P-Cat occurrence compared with PRISM. NARR shows a greater frequency of P-Cats across the Sierra Nevada compared with MERRA-2, however both datasets show considerable negative frequency biases across most of the West.

As with the maximum P-Cat comparisons, the primary difference for P-Cat frequency in Figure 11a is in the spatial variance. This reflects that all datasets capture the principal spatial patterns of P-Cat occurrence, but with varying frequency magnitudes. While TRMM shows similar spatial variability to PRISM at the CONUS scale, for the Midwest, Southeast, Northeast, and Southern Great Plains, TRMM shows higher spatial variability at the sub-regional scale, reflecting its positive and negative biases across the East and West, respectively (Figure 11b). This is not the case for the two reanalyses that show systematic low variance ratios across all sub-regions.

During SON, GHCN-D shows the highest frequency of P-Cat occurrence in the Northwest and Southeast with values exceeding 10 P-Cats per season along the coasts of Washington, Oregon, and northern California as well as in southeast Texas and southwest Louisiana (Figure 9a). Eastern North Carolina and Virginia also exhibit relatively high frequencies. There are many commonalities between the frequency map in Figure 9a and the maximum P-Cat map in Figure 5a, with many of the regions that experience high values of one also experiencing high values of the other. However, the stations that exhibit the highest P-Cat frequencies do not necessarily exhibit the highest maximum P- 
Cats. This is evident in some parts of the South and along the Atlantic Coast of Florida where heavy rainfall is common but does not approach high-end P-Cat magnitude.

Consistent with expectations based on the above results, the higher resolution TRMM and PRISM (Figure 9b,e) share the most similarities with GHCN-D. PRISM captures the overall spatial patterns and frequency magnitudes, but it is also capable of resolving small scale features such as higher frequencies over the southern Appalachian Mountains, over southern and western Arkansas, and to a lesser degree across the Bitterroot Mountains of Idaho and Montana. TRMM also resembles the station data in many respects, especially across the East. Over the Northwest, as in other analyses, TRMM's limitation at capturing frozen precipitation likely results in negative biases over the mountains, however it shows a positive frequency bias across the lower elevations of the coastal Northwest. NARR and MERRA-2 resemble each other with systematic low frequency bias across the CONUS (Figs $8 \mathrm{f}-\mathrm{h}$ ). Both reanalysis and TRMM show a positive frequency bias over a small area of the southern Washington Cascades, with respect to PRISM, which upon visual comparison with GHCN-D appears to be a shortcoming of PRISM rather than the other datasets. Similar to other results, TRMM is an outlier in the Taylor diagram in Figure 11c where four of the NCA sub-regions show similar or greater spatial variance compared with PRISM. The other datasets tend to show less spatial variance with pattern correlations generally between 0.6 and 0.9 .

During winter (Figure 10a), the P-Cat frequencies are highest across the mountains of Washington, Oregon, and California with elevated P-Cat frequencies also occurring in the higher elevations of Idaho, Utah, and Arizona. The high values here, exceeding $10 \mathrm{P}-$ 
Cats/season, are indicative of the frequent passage of midlatitude cyclones and the influence of orographic lifting. In contrast, the other area of high P-Cat occurrence is a broad swath of the South and southern Midwest where Gulf of Mexico moisture fuels heavy rain associated with midlatitude cyclones.

PRISM (Figure 10b) captures mountain ranges across the West and the general pattern in the East but with a lower frequency in some parts of the South (Figure 10e). PRISM underestimates the isolated high frequency P-Cats that GHCN-D captures over the higher terrain of Idaho, Utah, and Arizona. TRMM (Figure 10b) resembles both PRISM and GHCN-D, but with substantial high frequency biases over the lower elevations of the West Coast and throughout the East (Figure 10f). TRMM also shows negative biases along the immediate Pacific Coast, suggesting frozen precipitation is not the only contributor to the underestimation in the West. TRMM is also the only dataset to capture a relatively high frequency of P-Cats across the Northeast. A physical explanation for this widespread bias in TRMM is unclear as it is not consistent with findings from other seasons or at the annual scale. NARR and MERRA-2 are quite similar with overall negative frequency biases across the CONUS with the exception of the western valleys. The fact that TRMM, NARR, and MERRA-2 all show positive biases in the valleys of the West is suggestive of PRISM underestimating P-Cat frequencies here. This is qualitatively supported by a visual comparison between GHCND and PRISM frequencies over the Northern Central Valley of California and Willamette Valley of Oregon. The Taylor diagram in Figure 11d shows how TRMM is a dramatic 
outlier in the Southeast while all other datasets cluster together with small variance ratios over both the Southeast and Northwest.

\section{4: Annual P-Cat Occurrence}

Figures 12-14 show spatially aggregated P-Cat frequencies over time. Here we only show results for annual frequency at the CONUS scale, for DJF over the Northwest, and for SON over the Southeast sub-regions (see Figure 2) to capture the regions and corresponding seasons where high-end P-Cats are most common. In each figure, the left column shows the number of P-Cats per category on the native grid of each dataset, while the right column is when the datasets have been rescaled to the MERRA-2 grid. This means that all things equal, on the left the coarser resolution datasets will have a lower frequency of P-Cat occurrence compared with the higher resolution datasets simply because there are more data points in the high-resolution cases. In this sense, the left column is intended for relative qualitative comparison while the right column compares datasets with an equal number of data points.

For most years the full range of P-Cats occurs somewhere over the CONUS (Figure 12a). There is also an apparent positive trend in the number of P-Cat $1 \mathrm{~s}$ over the period of record while other P-Cats do not display a trend; however, no trend was found to be statistically significant at the $5 \%$ confidence interval using a bootstrapping significance assessment. Comparing each dataset to GHCN-D, all exhibit a similar positive trend in PCat occurrence and a similar evolution of interannual variability. For example, the year 2000 shows a minimum in P-Cat 2 s in all datasets. Consistent with results from Figures 4-11, PRISM (Figure 12b) shows the most high-end P-Cats while NARR and MERRA-2 
(Figures 12d,e) show the least. When compared on a common grid, P-Cat 1 frequencies are generally comparable across the suite, with the exception of NARR (Figure 12h). PRISM (Figure 12f) maintains the greatest number of high-end P-Cats further supporting high native resolution as an important factor in capturing the frequency of very extreme three-day totals. The coefficients of variation for each P-Cat time series, computed as the standard deviation of each dataset's annual frequency divided by its mean, are recorded in Table 2. All datasets show a greater year-to-year variability in higher-end P-Cats relative to lower-end P-Cats. For example, GHCN-D has a coefficient of variation for the annual frequency of P-Cat $5 \mathrm{~s}$ that exceeds that of P-Cat $1 \mathrm{~s}$ by a factor of 10 .

During SON over the Southeast (Figure 13), GHCN-D shows a high number of P-Cat 4 and 5s occurring during 1998 and 1999 (Figure 13a) with considerable interannual variability throughout the record. Unlike at the CONUS scale, there is no apparent trend in any of the P-Cat frequencies. PRISM (Figure 13b) continues to show the greatest number of high-end P-Cats compared with the other datasets. TRMM also captures higher-end P-Cats in the early part of the record (Figure 13c), including 1999. NARR and MERRA-2 (Figures 13d,e) show primarily P-Cat 1 and 2s, with MERRA-2 showing some P-Cat 3s in 1998 and 1999, suggesting that it realistically represents the high-end PCats captured in the finer resolution datasets but with diminished magnitude due to a coarser grid. When compared on a common grid, dataset agreement is much stronger, although NARR stands out as having the lowest P-Cat occurrence, with similar interannual variability. The coefficient of variation results continue to show greater variability among the most extreme P-Cats across the five-dataset suite (Table 3). 
For DJF in the Northwest sub-region (Figure 14), GHCN-D displays an apparent positive trend in the frequency of P-Cat 1 and 2s (Figure 14a), both of which also make up the vast majority of P-Cats. Neither trend is statistically significant. All datasets except for TRMM agree on the increasing frequency of P-Cat 1s over this time period, yet considerable differences exist in other aspects of the wintertime frequency of P-Cats. The differences are most acute when comparing TRMM with other datasets, likely due to limitations at capturing the high proportion of P-Cats that fall as snow over higher terrain. GHCN-D and PRISM (Figures 14a,b) show the most qualitative agreement including with interannual variability and P-Cat trends, with NARR also sharing commonalities in year-to-year fluctuations (Figure 14d). When compared on common grids, overall magnitudes of P-Cat 1s are in reasonable agreement across the suite, however interannual variability is still different in TRMM (Figure 14g) compared with PRISM and NARR (Figures 14f,h), while MERRA-2 (Figure 14e) and TRMM share commonalities. These results further suggest using caution when measuring and monitoring extreme precipitation across areas of complex terrain where orographic effects on precipitation are key and extremes are often associated with frozen precipitation. The dataset's annual PCat frequency results for DJF in the Northwest continue to show greater interannual variability as the P-Cats increase (Table 4).

\section{5: Global Precipitation Measurement (GPM) Intercomparison}

Considering the potential benefits of using remote sensing to continuously monitor and track extreme precipitation over time, we compare GPM data to its predecessor, TRMM, in Figure 15. GPM has only been online for a short time, prohibiting a 
comprehensive climatology intercomparison. We therefore leverage the existing overlap period (April 2014-December 2015) using the maximum observed P-Cats as well as total observed P-Cat frequency per grid cell/station for comparison. Over this two-year period, there is some indication that GPM captures more small-scale features and better represents extremes over the mountainous West (Figure 13d) compared with TRMM (Figure 13b). These results are likely attributable, at least in part, to GPM's higher spatial resolution, but may also be due to improvements in GPM at measuring snow (Hou et al. 2014). This qualitatively brings GPM closer to GHCN-D in most cases with exceptions. For example, GPM does a poorer job at capturing the band of P-Cat 2s stretching from northeast Texas through Missouri compared with TRMM and overestimates P-Cat magnitude over eastern Tennessee and northern Alabama. P-Cat frequencies reveal similarities between TRMM and GPM (Figure 15d). 


\section{Chapter 5: Summary, Conclusions, and Implications for Future Work}

\section{1: Summary and Conclusions}

Here we present a categorization scheme for monitoring and tracking change in extreme precipitation over space and time. The approach assigns a category between one and five to three-day storm totals (Figure 2). Intended as a novel way to track extreme precipitation as a climate indicator, this tool works to provide a platform for monitoring change in extreme precipitation across scales, datasets, time, and geography by leveraging high-resolution satellite-based gridded precipitation data over the CONUS. Comparison of a diverse suite of high resolution gridded and in situ datasets across the CONUS revealed inconsistencies in extreme precipitation climatology suggesting data choice matters when tracking trends and monitoring change. Furthermore, the P-Cat scheme proves a useful and intuitive way to assess observational uncertainty across a wide range of precipitation estimation techniques.

Specific to this dataset intercomparison, all gridded datasets captured the principal spatial patterns of mean annual precipitation climatology, with primary differences related to grid resolution and its impact on resolving influential orography (Figure 3). Focusing on extremes, the magnitude (Figures 4-7) and frequency of P-Cats (Figures 711) are assessed using the P-Cat scheme as a metric for intercomparison. In general, the higher resolution datasets more closely resemble gauge data across the CONUS and seasons. Specifically, PRISM shares many detailed commonalities with station data, while the next highest resolution dataset, TRMM, is also similar overall. NARR and MERRA-2 reanalysis show systematically lower magnitude and frequency of P-Cats 
across the CONUS and seasonal cycle. TRMM shows systematically lower P-Cat magnitudes and frequencies across the mountains of the West during fall and winter when a large portion of precipitation falls as snow, consistent with known limitations of TRMM at capturing frozen precipitation. When all datasets are upscaled to a common coarser grid, differences persist but are reduced. The annual occurrence of P-Cats shows similar differences across the suite, with a general positive relationship between grid resolution and the number of P-Cats (Figures 12-14). Preliminary assessment of GPM, the follow-on satellite product to TRMM, suggests some potential improvements over TRMM in capturing frozen precipitation and fine scale extremes (Figure 15). Ultimately, results suggest satellite data show promise in capturing the overall patterns of heavy precipitation climatology, which could lead to improved monitoring in regions with sparse ground observations.

The effect of spatial scale on the ability of a dataset to capture high-end P-Cats is in general not surprising. At coarser resolutions, extremes are reduced through spatial smoothing, leading to a systematic contraction of the tails of the distribution. However, after regridding to a common coarser grid, the datasets with the highest native spatial resolution generally continue to show the highest magnitude and frequency of P-Cats. This is suggestive of two things. First, a dataset being produced at high resolution allows it to capture extremes in both magnitude and frequency that simply could not be captured at a coarser grid. In this sense, even though regridding may reduce the magnitude of extremes through spatial smoothing, datasets that were originally at a high resolution would still maintain higher-end extremes than datasets originally at a lower resolution. 
The second likely contributor to this difference is that grid resolution is not the only factor influencing the level of similarity or dissimilarity between products. In the case of this study, all datasets are produced using different approaches to assimilate and/or interpolate data. These differences are likely to be manifested as particularly acute when assessing extreme precipitation, which is inherently rare, occurs at small scales, and is often influenced by orography; all processes that are challenging to observe and assimilate.

\subsection{Limitations and Caveats}

We acknowledge some assumptions and limitations in our methodology. First, the use of fixed thresholds for the entire CONUS is intended to highlight the heaviest precipitation three-day totals across the domain in an intuitive way. As such, some drier regions do not record P-Cats, even though smaller totals may be considered impactful relative to the local climatology. The synoptic scale of measurement also captures totals at a temporal scale often associated with impacts such as flooding and landslides (Ralph and Dettinger 2012) but does not distinguish between shorter and longer duration totals. This may be impactful for lower-end P-Cats that could result from short duration extreme convective events associated with different impacts than longer duration synoptic events. It is possible that a single storm may be counted more than once due to the moving threeday window used to construct the P-Cat scheme. While spatial regridding is used to compare the datasets on a common grid, regridding inherently introduces some bias that may be more acute at the tails of the distribution. As such, details of results could be sensitive to the regridding approach, although we would not expect the overall 
conclusions to be altered by such sensitivity. Additionally, the Taylor statistics, used to quantify the degree of pattern correspondence among the products, do not account for spatial autocorrelation which has the potential to influence the results. Finally, while we include the five datasets here in effort to capture a range of measurement methods while focusing on high resolution products, this analysis could be extensible to other observations.

\section{3: Broader Implications and Future Direction}

Overall, the P-Cat gridded data categorization scheme introduced here offers several opportunities for future research, including refinement of the technique as well as ways to monitor and track extreme precipitation over time. As a target for climate model evaluation, the P-Cat approach would provide a novel measure of model skill at realistically simulating extreme precipitation climatology. While the P-Cat scheme is intuitive in that it utilizes a single fixed threshold for each category, a flexible set of PCat thresholds that can be customized for a given dataset could also benefit dataset evaluation. The P-Cat scheme is also well-designed for assessing future projections of changes in extreme precipitation totals in climate models. As an intuitive monitoring tool, it has the opportunity to offer regionally relevant information about extreme precipitation climatology useful to a number of stakeholders and decision makers, including urban planners and environmental managers. Ultimately, the P-Cat approach is easily extensible to other regions of the world, facilitating temporal and spatial tracking and monitoring of extremes, dataset intercomparison, model evaluation, and future change assessment. 


\begin{tabular}{|l|l|l|l|l|l|l|}
\hline $\begin{array}{l}\text { Agency } \\
\text { Source }\end{array}$ & Dataset & $\begin{array}{l}\text { Spatial } \\
\text { Resolution }\end{array}$ & $\begin{array}{l}\text { Temporal } \\
\text { Resolution }\end{array}$ & Data Source & Reference \\
\hline NASA & TRMM & $\begin{array}{l}\text { Tropical } \\
\text { Rainfall } \\
\text { Measuring } \\
\text { Mission }\end{array}$ & $0.25^{\circ} \times 0.25^{\circ}$ & 3 -hourly & Satellite & $\begin{array}{l}\text { Huffman } \\
\text { et al. } \\
(2007)\end{array}$ \\
\hline NASA & GPM & $\begin{array}{l}\text { Global } \\
\text { Precipitation } \\
\text { Measuring } \\
\text { Mission }\end{array}$ & $0.1^{\circ} \times 0.1^{\circ}$ & 30 -minute & Satellite & $\begin{array}{l}\text { Hou et al. } \\
(2014)\end{array}$ \\
\hline OSU & PRISM & $\begin{array}{l}\text { Parameter- } \\
\text { elevation } \\
\text { Regressions } \\
\text { Independent } \\
\text { Slopes Model }\end{array}$ & $0.04^{\circ} \times 0.04^{\circ}$ & Daily & $\begin{array}{l}\text { Gridded in } \\
\text { situ station } \\
\text { data }\end{array}$ & $\begin{array}{l}\text { Daly et al. } \\
(1994)\end{array}$ \\
\hline NASA & MERRA-2 & $\begin{array}{l}\text { Modern-Era } \\
\text { Retrospective } \\
\text { analysis, } \\
\text { version } 2\end{array}$ & $0.625^{\circ} \times 0.5^{\circ}$ & 3 -hourly & $\begin{array}{l}\text { Global } \\
\text { reanalysis }\end{array}$ & $\begin{array}{l}\text { Gelaro et } \\
\text { al. (2017) }\end{array}$ \\
\hline NCEP & NARR & $\begin{array}{l}\text { North } \\
\text { American } \\
\text { Regional } \\
\text { Reanalysis }\end{array}$ & $32 \mathrm{~km} \times 32 \mathrm{~km}$ & 3-hourly & $\begin{array}{l}\text { Regional } \\
\text { reanalysis } \\
\text { with gauge } \\
\text { assimilation }\end{array}$ & $\begin{array}{l}\text { Mesinger } \\
\text { et al. } \\
\text { (2006) }\end{array}$ \\
\hline NOAA & GHCN-D & $\begin{array}{l}\text { Global } \\
\text { Historical } \\
\text { Climatology } \\
\text { Network }\end{array}$ & $\begin{array}{l}\text { In situ station } \\
\text { data }\end{array}$ & $\begin{array}{l}\text { Menne et } \\
\text { al. (2012) }\end{array}$ \\
\hline
\end{tabular}

Table 1. Datasets used in the intercomparison and the associated specifications. 


\begin{tabular}{|c|c|c|c|c|c|}
\hline \multicolumn{6}{|c|}{ Coefficients of Variation } \\
\hline \multicolumn{6}{|c|}{ Annual P-Cat Frequency: CONUS } \\
\hline & P-Cat 1 & P-Cat 2 & P-Cat 3 & P-Cat 4 & P-Cat 5 \\
\hline GHCN-D & 0.0835 & 0.2429 & 0.4011 & 0.8138 & 1.2412 \\
\hline PRISM & 0.1029 & 0.3006 & 0.6062 & 0.9093 & 1.3144 \\
\hline TRMM & 0.1405 & 0.4684 & 1.266 & 2.1452 & 3.9733 \\
\hline NARR & 0.1595 & 0.5436 & 1.3027 & & \\
\hline MERRA-2 & 0.253 & 0.8748 & 2.4149 & & \\
\hline
\end{tabular}

Table 2. Dataset's coefficient of variation values for each P-Cat's annual frequency across the CONUS. 


\begin{tabular}{|c|c|c|c|c|c|}
\hline \multicolumn{6}{|c|}{ Coefficients of Variation } \\
\hline \multicolumn{6}{|c|}{ SON P-Cat Frequency: Southeast } \\
\hline & P-Cat 1 & P-Cat 2 & P-Cat 3 & P-Cat 4 & P-Cat 5 \\
\hline GHCN-D & 0.4114 & 0.7065 & 0.9702 & 1.5806 & 2.4336 \\
\hline PRISM & 0.4526 & 0.7257 & 1.2772 & 1.7735 & 2.1558 \\
\hline TRMM & 0.539 & 0.6824 & 1.7924 & 2.9138 & 3.9733 \\
\hline NARR & 0.5587 & 1.1197 & 4.1477 & & \\
\hline MERRA-2 & 0.6349 & 1.1265 & 2.5196 & & \\
\hline
\end{tabular}

Table 3. Same as in Table 2 except for SON and only over the Southeast sub-region. 


\begin{tabular}{|c|c|c|c|c|c|}
\hline \multicolumn{6}{|c|}{ Coefficients of Variation } \\
\hline \multicolumn{6}{|c|}{ DJF P-Cat Frequency: $N W$} \\
\hline & P-Cat 1 & P-Cat 2 & P-Cat 3 & P-Cat 4 & P-Cat 5 \\
\hline GHCN-D & 0.1708 & 0.4533 & 1.1307 & 2.4443 & 4.2136 \\
\hline PRISM & 0.1811 & 0.4614 & 0.8834 & 1.53 & 1.8329 \\
\hline TRMM & 0.4746 & 1.2636 & 3.9733 & & \\
\hline NARR & 0.314 & 1.2117 & 2.2976 & & \\
\hline MERRA-2 & 0.5393 & 2.3924 & & & \\
\hline
\end{tabular}

Table 4. Same as in Table 2 except for DJF and only over the Northwest sub-region. 


\begin{tabular}{|l|} 
P-Cat 1: $100<\mathrm{P}<200 \mathrm{~mm}$ \\
P-Cat 2: $200<\mathrm{P}<300 \mathrm{~mm}$ \\
P-Cat 3: $300<\mathrm{P}<400 \mathrm{~mm}$ \\
P-Cat 4: $400<\mathrm{P}<500 \mathrm{~mm}$ \\
P-Cat 5: $\mathrm{P}>500 \mathrm{~mm}$
\end{tabular}

Figure 1. P-Cat thresholds and associated colors used in subsequent figures. 


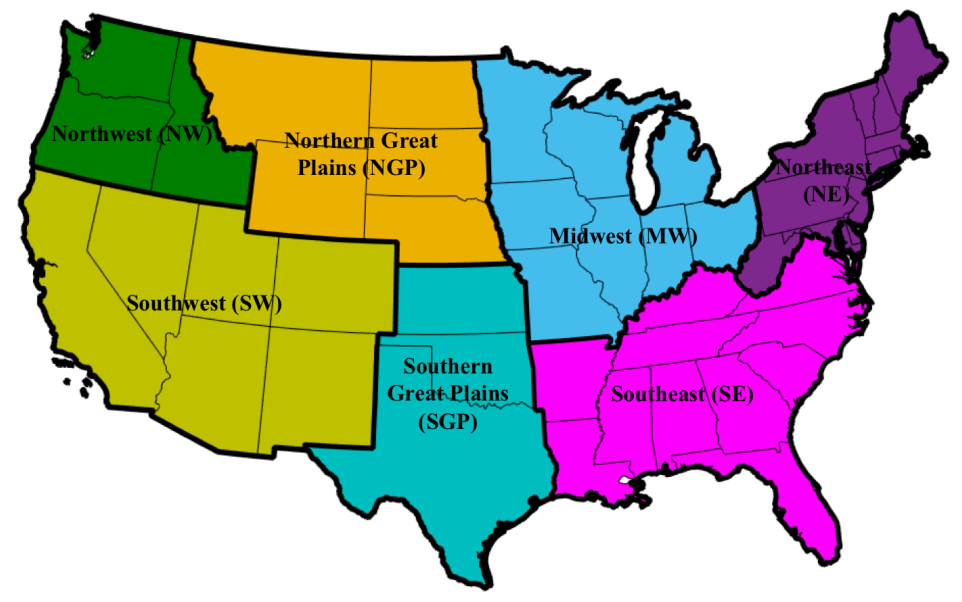

Figure 2. The seven NCA sub-regions and the associated abbreviations. 


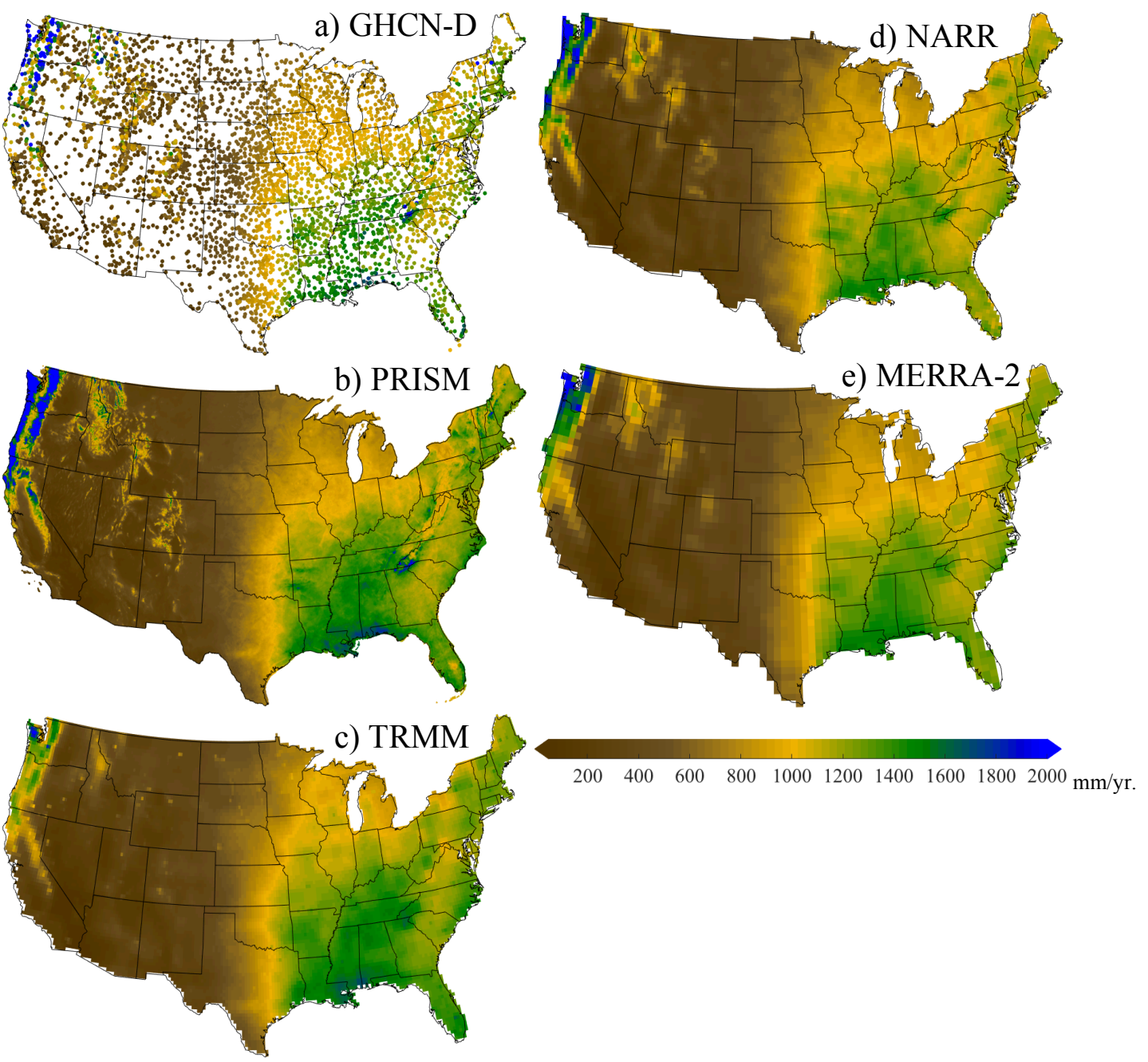

Figure 3. Average annual precipitation over the period of 1998-2015. Results are for (a) GHCN-D, (b) PRISM, (c) TRMM, (d) NARR, and (e) MERRA-2. 

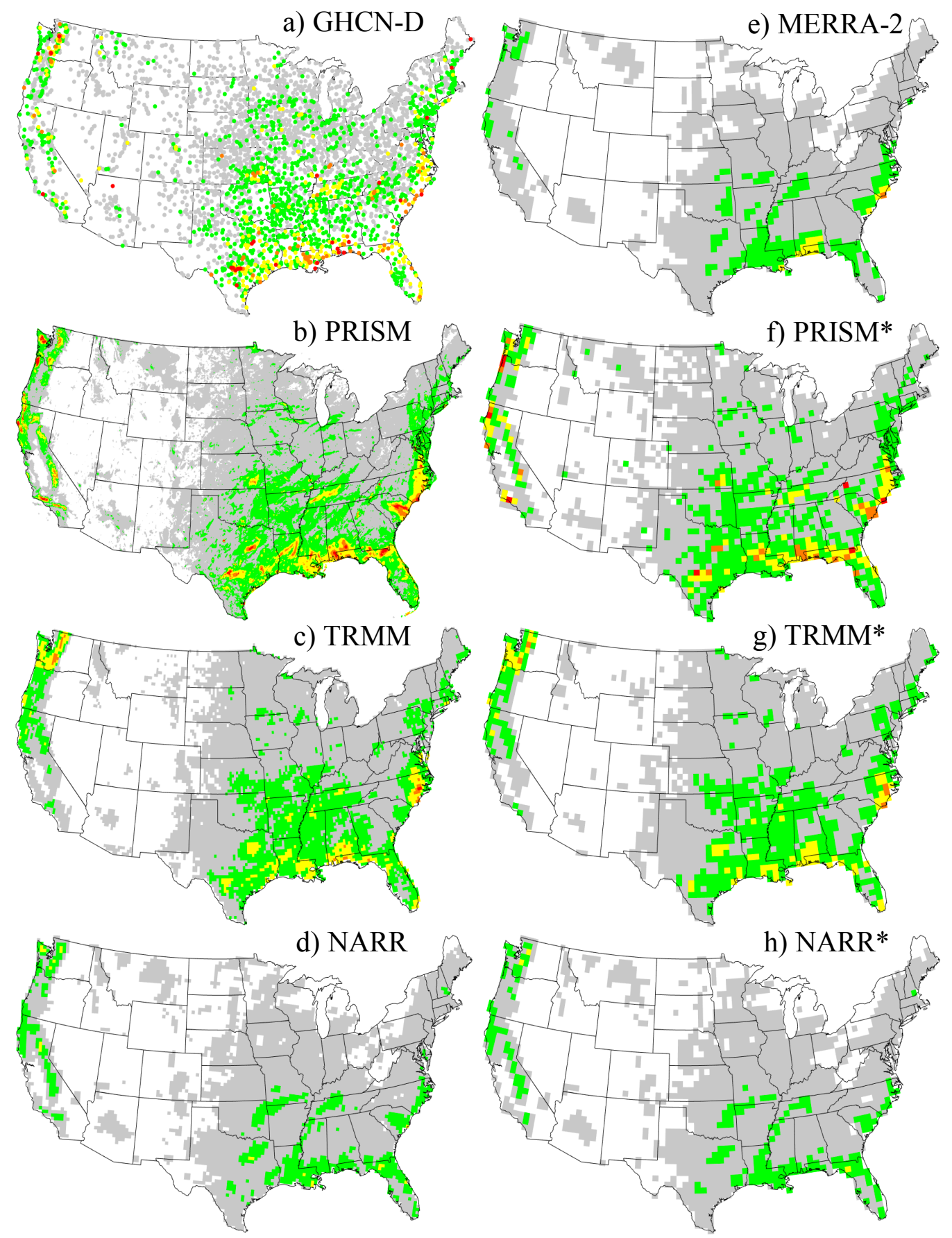

Figure 4. Maximum observed P-Cat at each grid point over the 1998-2015 period. (a-d) Maximum P-Cats on native grid, (e-h) maximum P-Cats on common MERRA-2 grid. 
Regridded datasets are indicated with an asterisk. Color scale is as in Figure 1. Un-shaded grid cells indicate that no P-Cat has occurred during the data record. 

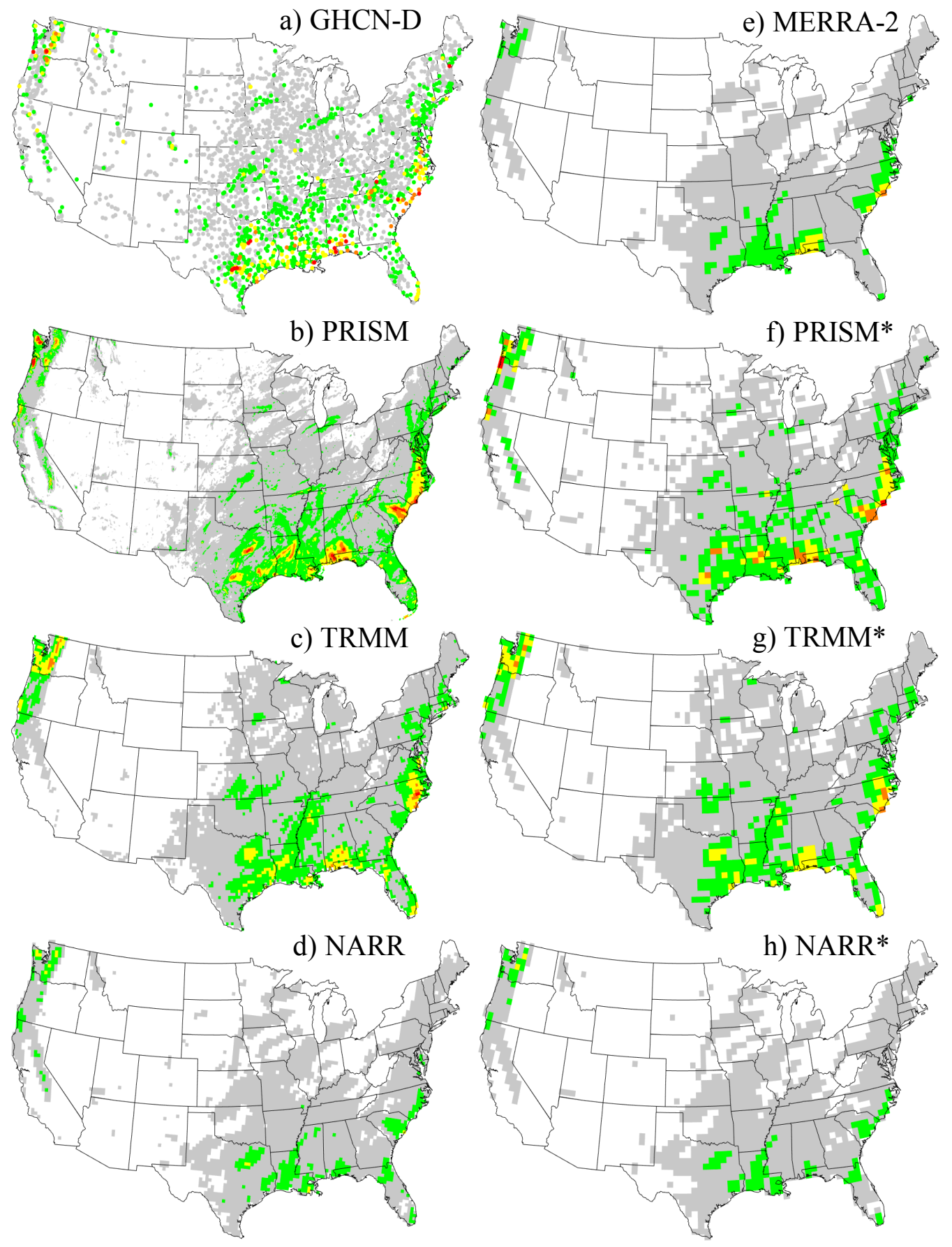

Figure 5. Same as in Figure 4 except for SON. 

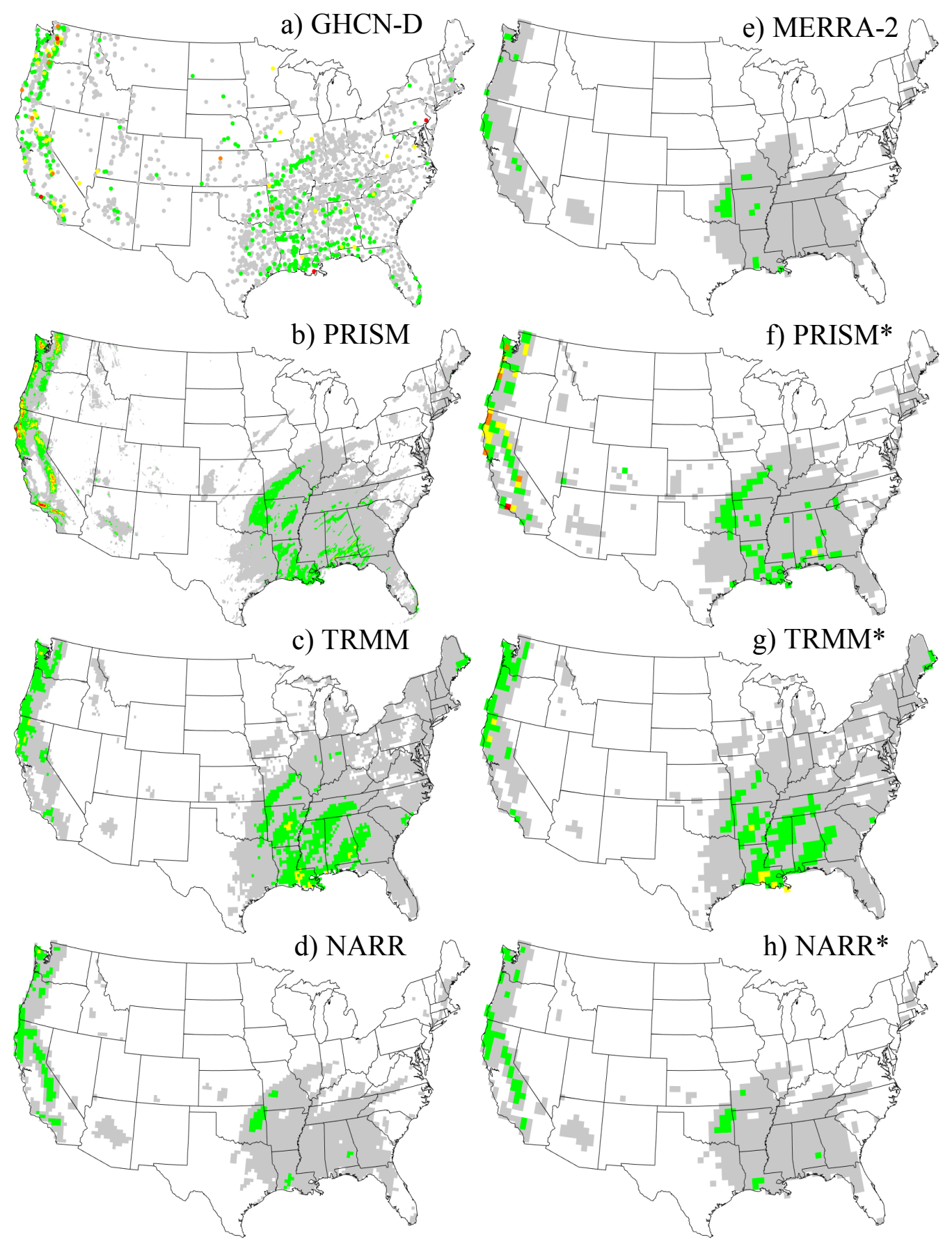

Figure 6. Same as in Figure 4 except for DJF. 

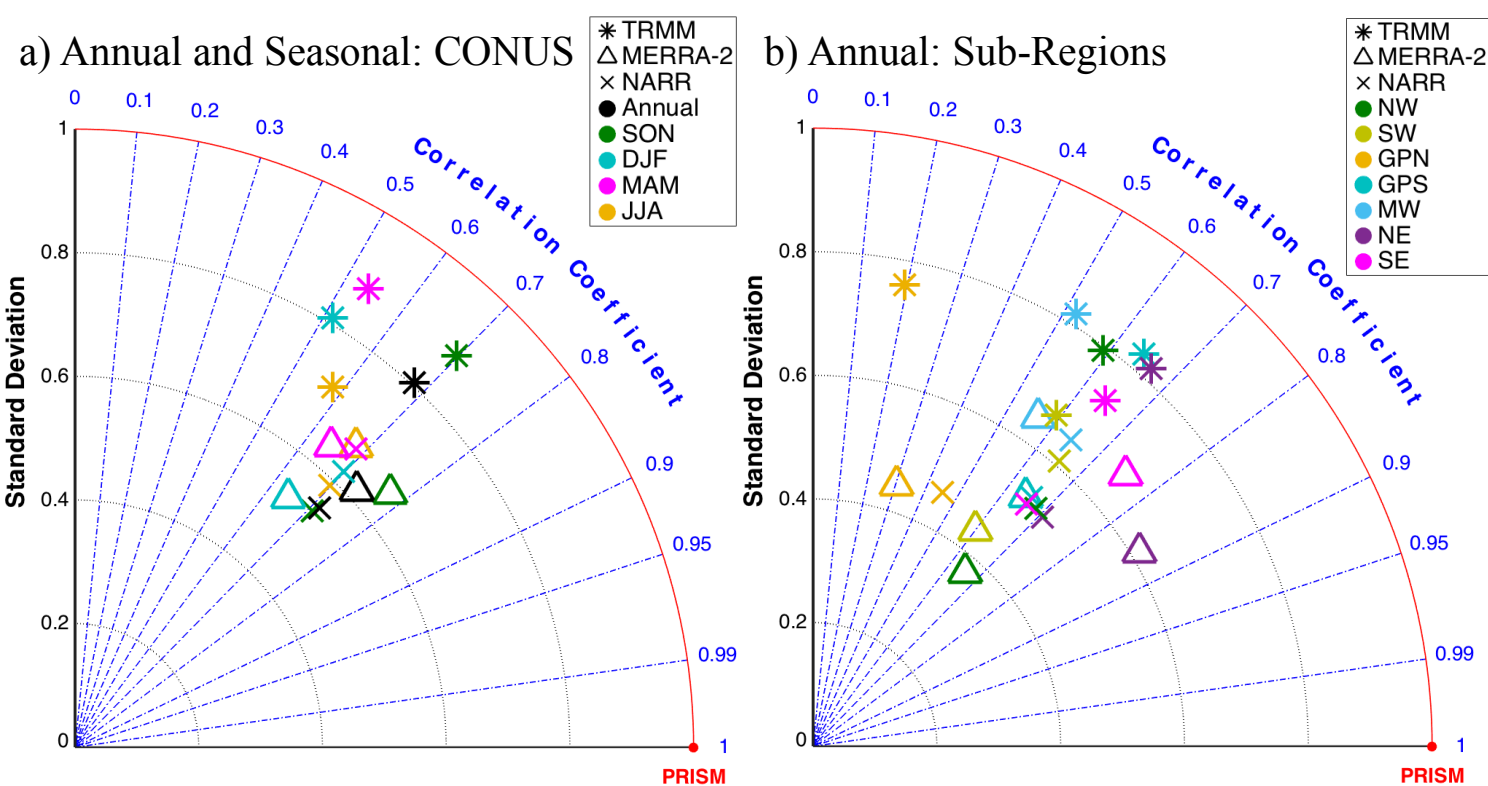

c) SON: Sub-Regions

d) DJF: Sub-Regions
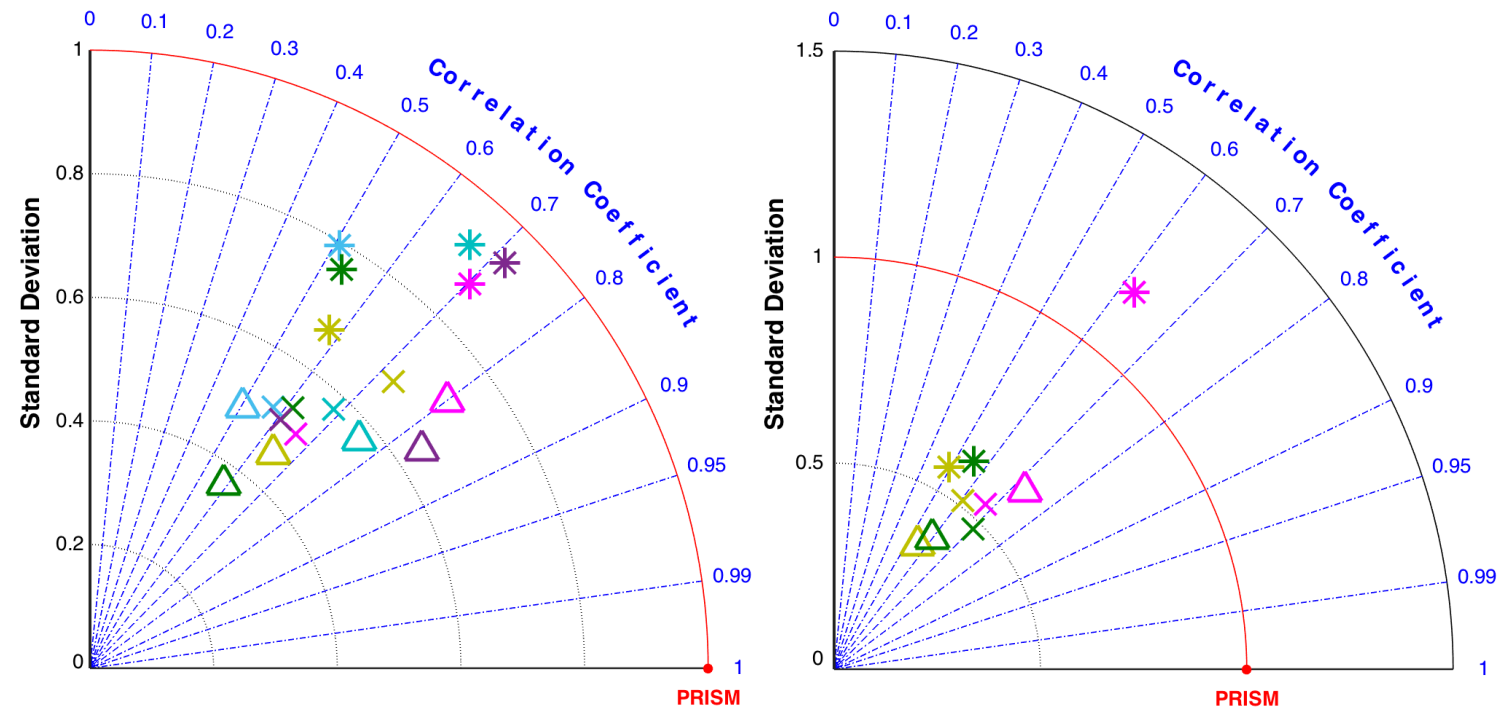

Figure 7. Taylor diagrams quantifying the spatial correspondence of the maximum observed P-Cats for TRMM, MERRA-2, and NARR relative to PRISM. Results are for (a) the CONUS annually and seasonally and relevant NCA sub-regions (b) annually and seasonally for (c) September, October, November and (d) December, January, February. Each dataset is labeled by a symbol with each season and sub-region assigned a color as 
defined in the legends in the top two panels. The $\mathrm{x}$ and $\mathrm{y}$ axes correspond to the standard deviation ratio between the indicated dataset and PRISM. The radial axis is the pattern correlation, and the distance between the symbol and the PRISM location is proportional to the centered root mean squared difference between the spatial field of the maximum PCats of the indicated dataset and PRISM, normalized by the spatial standard deviation of the PRISM field. 

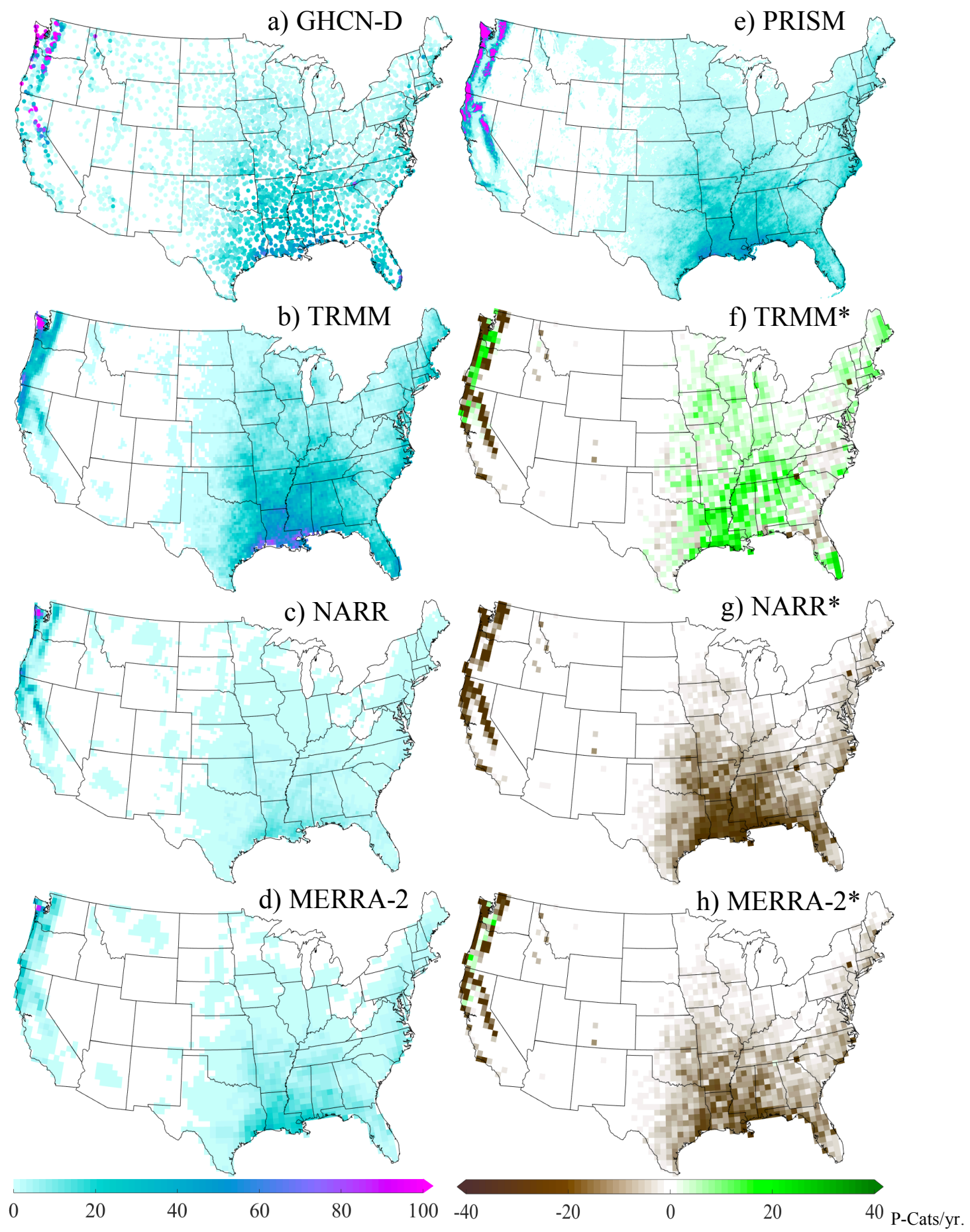

Figure 8. (a-e) Mean annual frequency of P-Cat occurrence over the 1998-2015 record, (f-h) the frequency bias is recorded as the difference between the mean annual frequency 
of P-Cat occurrence in the indicated dataset and PRISM. Frequencies are recorded as the number of P-Cats per year. Regridded datasets are indicated with an asterisk. 

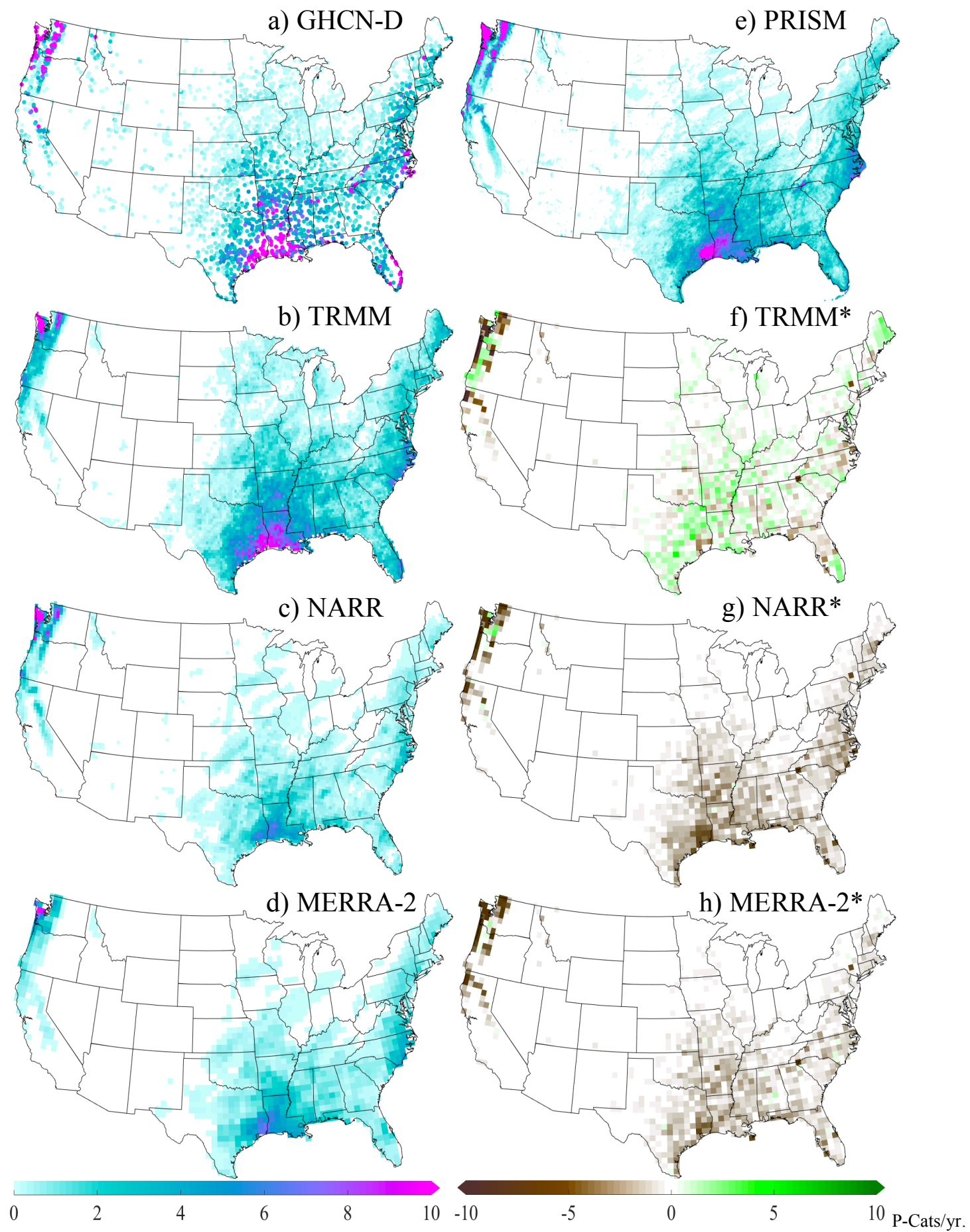

Figure 9. Same as in Figure 8 except for SON. 

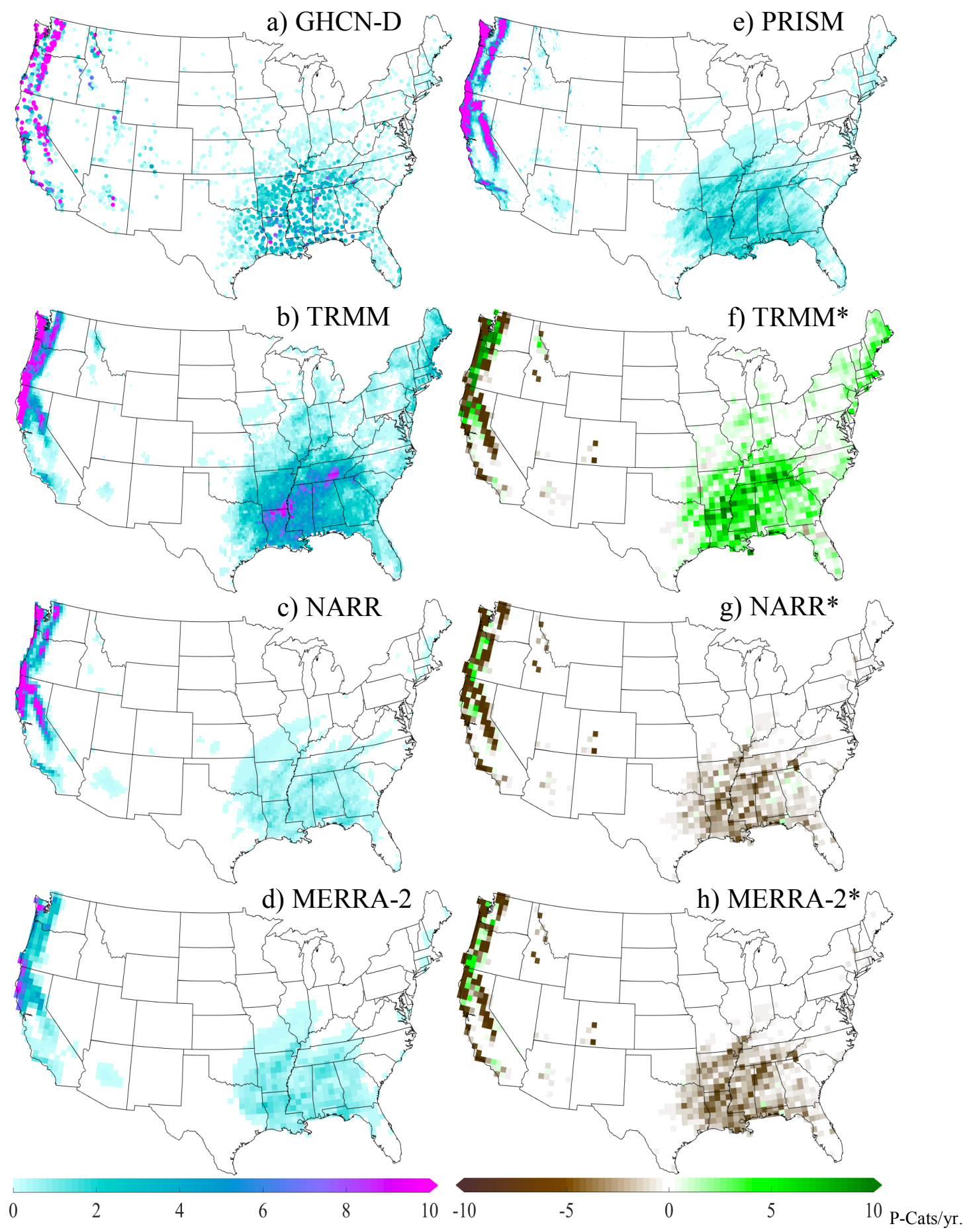

Figure 10. Same as in Figure 8 except for DJF. 

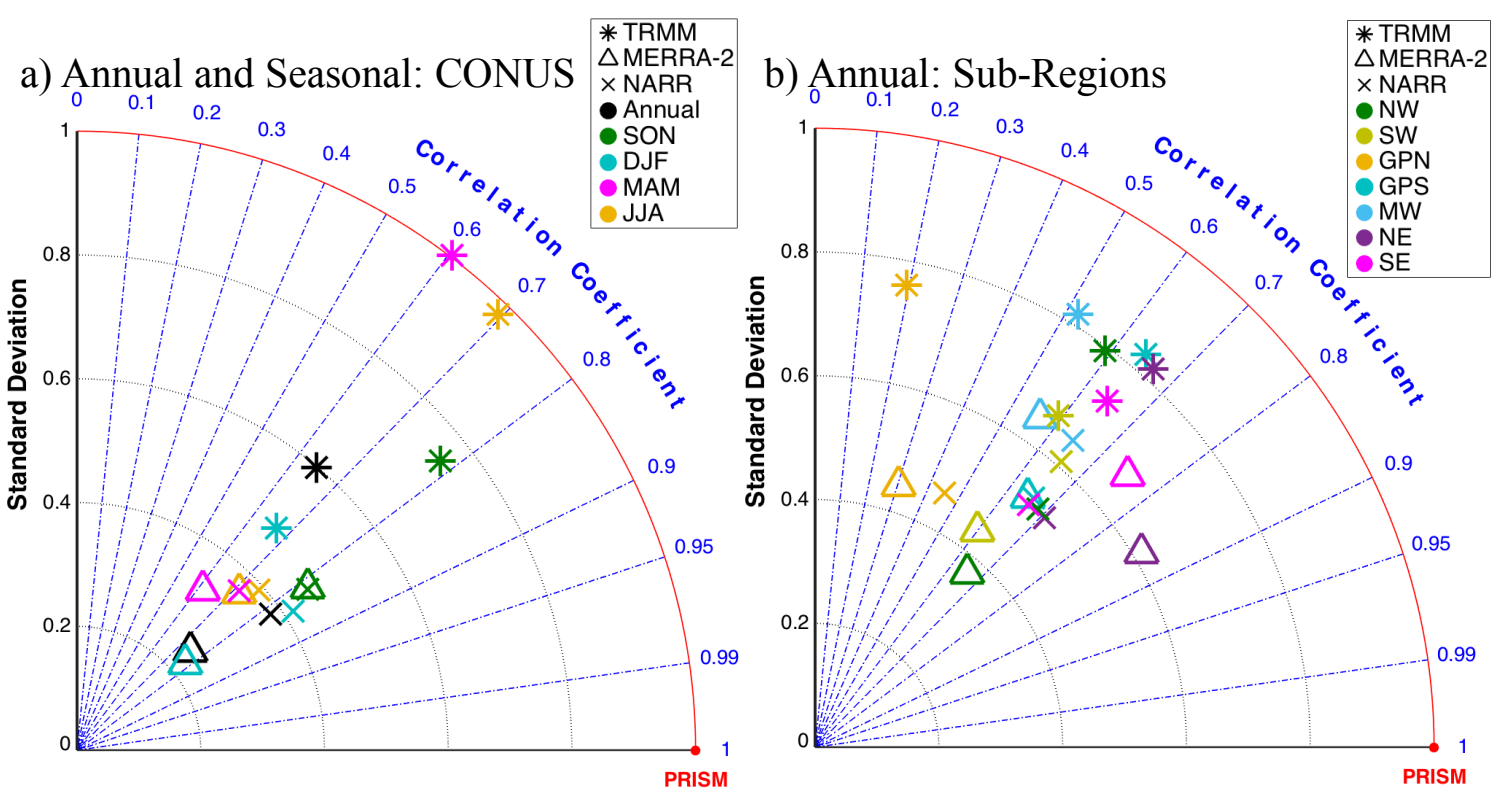

c) SON: Sub-Regions

d) DJF: Sub-Regions
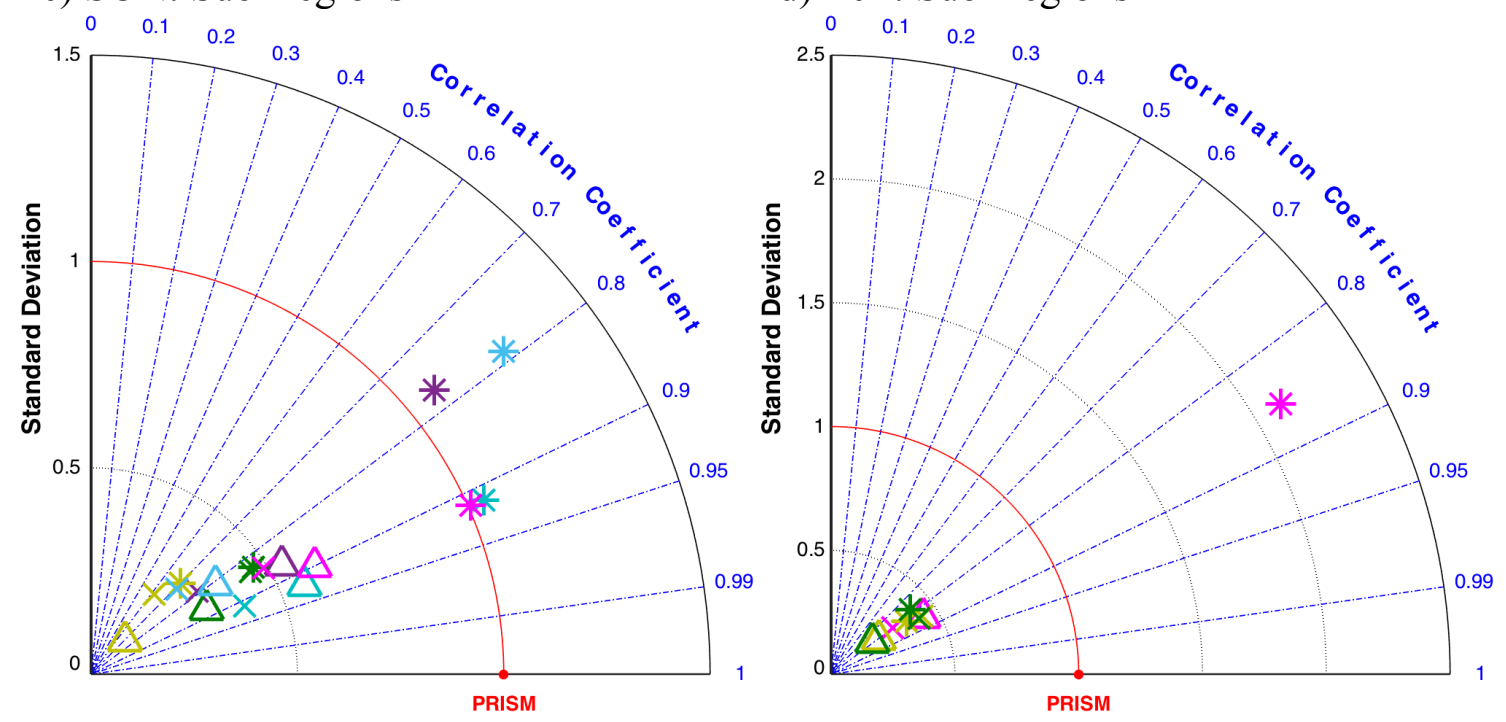

Figure 11. Same as in Figure 7 except for the mean frequency of P-Cat occurrence patterns. 

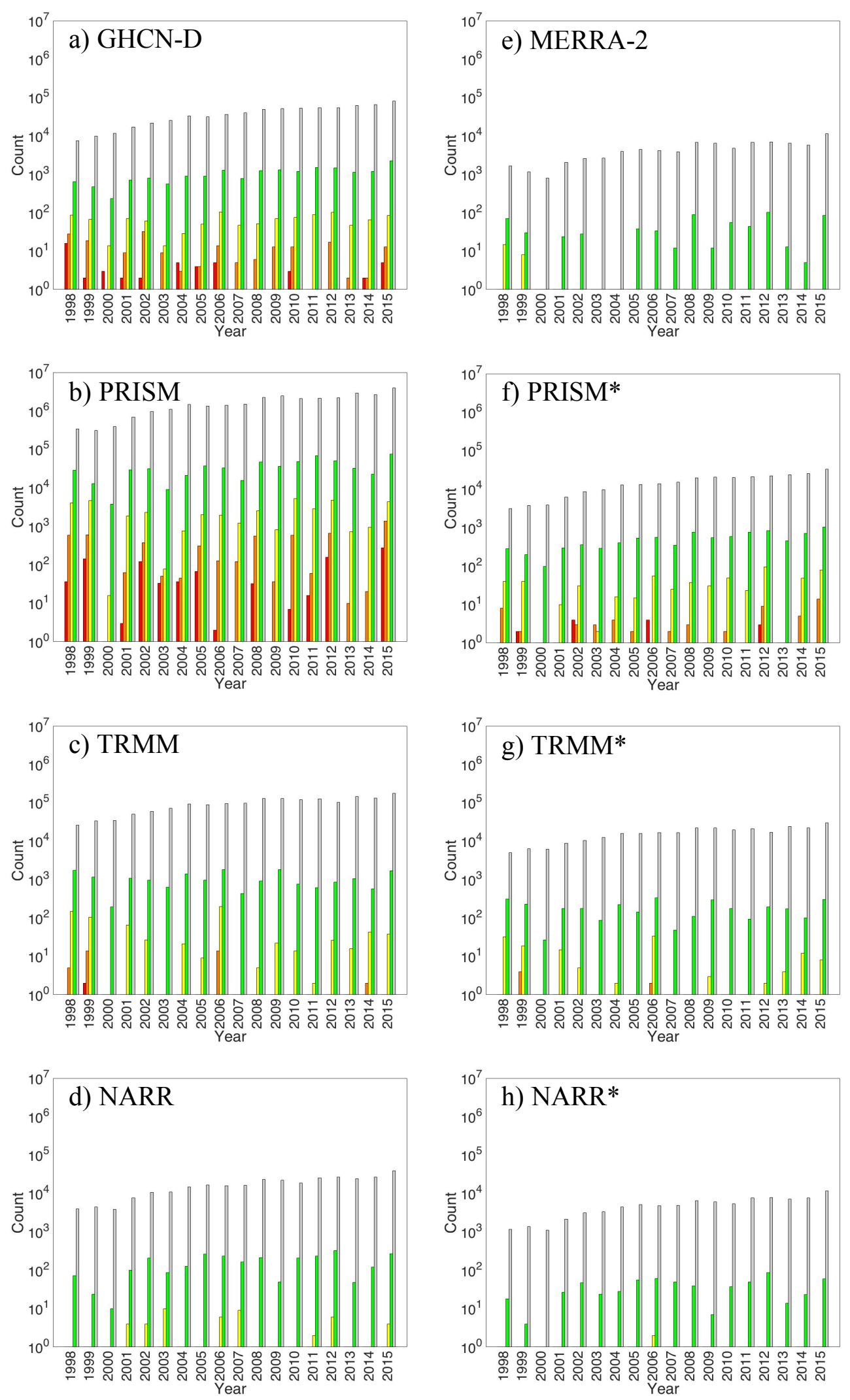

52 
Figure 12. Annual frequency of observed P-Cats over the 1998-2015 period. (a-d) Annual frequency of P-Cats on native grid, (e-h) annual frequency of P-Cats on common grid. Regridded datasets are indicated with an asterisk. Gray bars represent P-Cat 1, green PCat 2, yellow P-Cat 3, orange P-Cat 4, and red P-Cat 5 as in the legend in Figure 1. Results are plotted on a log scale. 

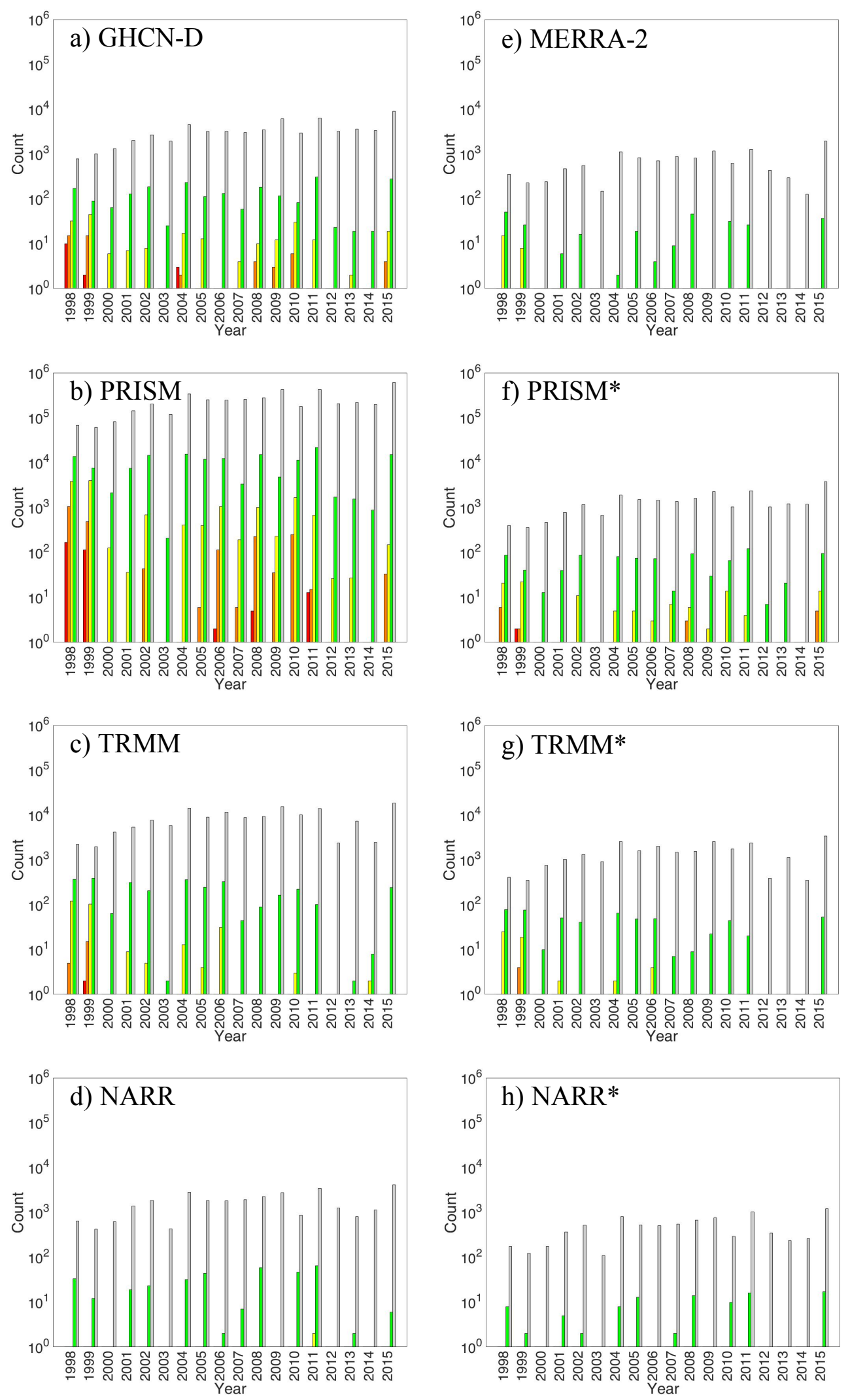
Figure 13. Same as in Figure 12 except for SON and only over the Southeast sub-region. 

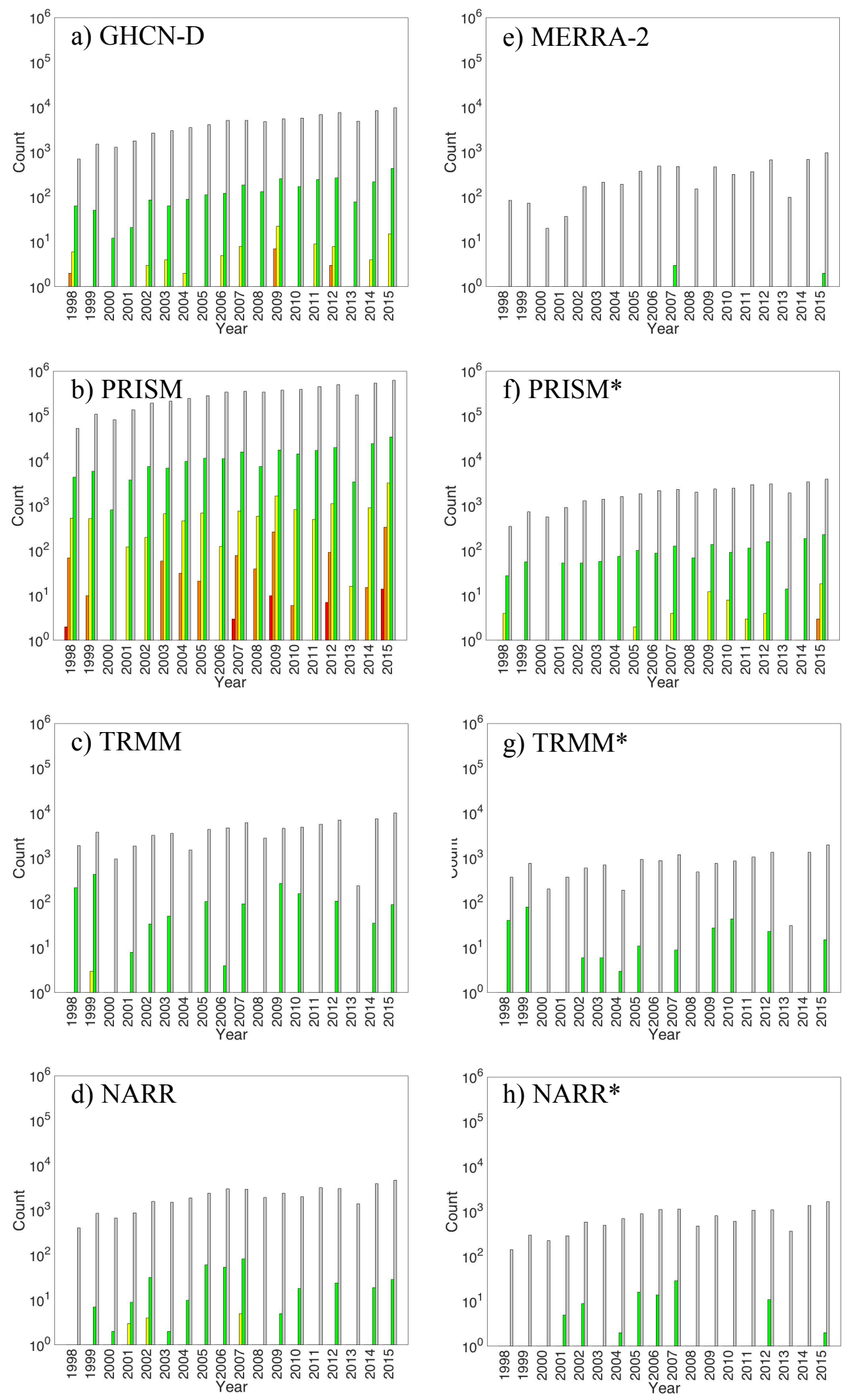
Figure 14. Same as in Figure 12 except for DJF and only over the Northwest sub-region. 

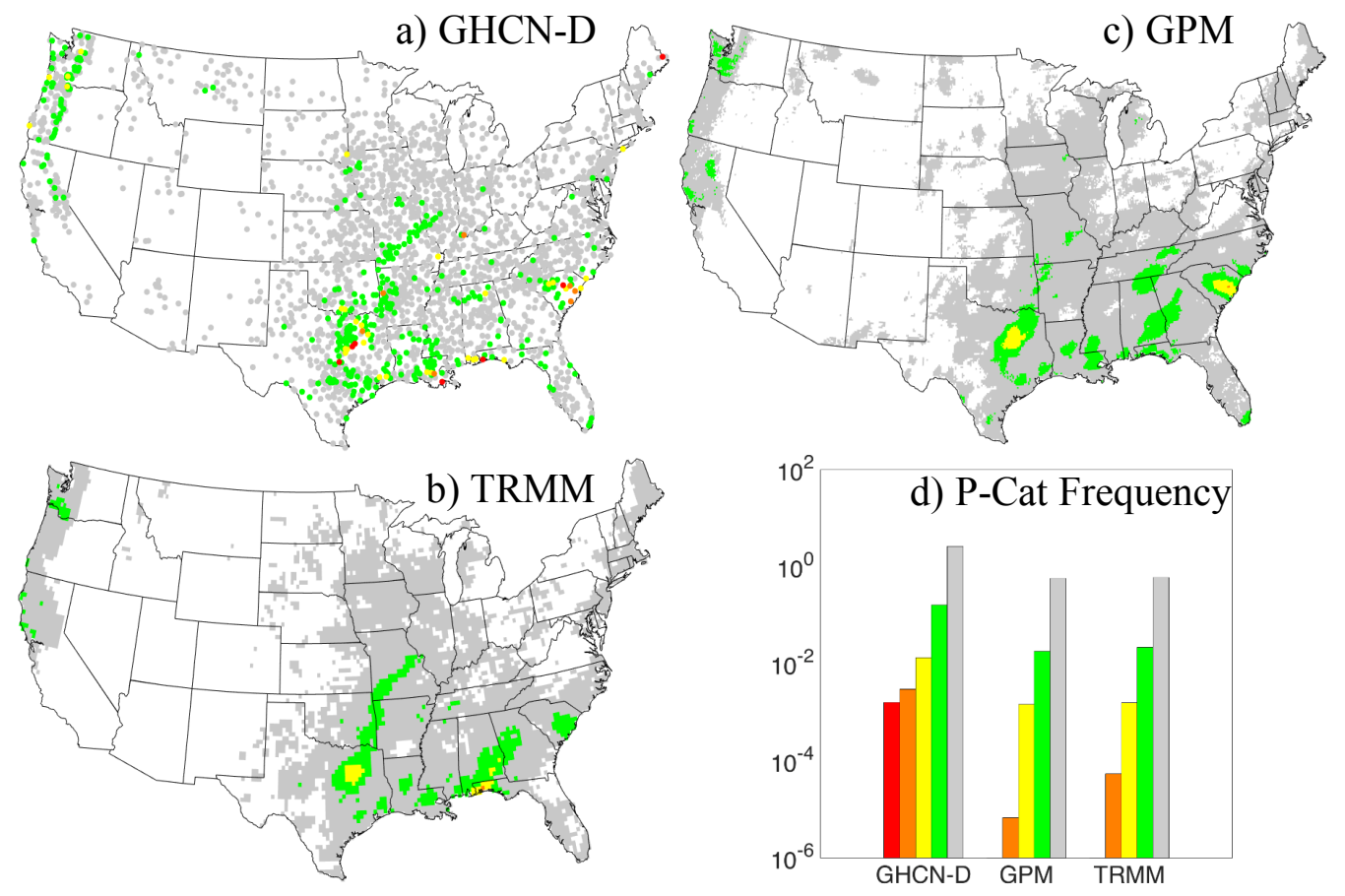

Figure 15. Maximum observed P-Cats during April 2014-December 2015, the TRMM/GPM overlap period. Results are for (a) GHCN-D, (b) GPM, (c) TRMM, (d) PCat frequency per grid cell/station observed over the time record. 


\section{References}

Adler, R. F., C. Kidd, G. Petty, M. Morissey, and H. M. Goodman, 2001: Intercomparison of Global Precipitation Products: The Third Precipitation Intercomparison Project (PIP-3). Bull. Amer. Meteor. Soc., 82, 1377-1396, doi:https://doi.org/10.1175/1520-0477(2001)082<1377:IOGPPT>2.3.CO;2.

Alexander, L. V., and Coauthors, 2006: Global observed changes in daily climate extremes of temperature and precipitation. J. Geophys. Res., 111, D05109, doi:05110.01029/02005JD006920.

Allen, M. R., and W. J. Ingram, 2002: Constraints on future changes in climate and the hydrological cycle. Nature, 419, 224-232.

Behrangi, A., K. Andreadis, J. B. Fisher, F. J. Turk, S. Granger, T. Painter, and N. Das, 2014: Satellite-based precipitation estimation and its application for streamflow prediction over mountainous western U.S. basins. J. Appl. Meteor. Climatol., 53, 28232842, doi:https://doi.org/10.1175/JAMC-D-14-0056.1.

Behrangi, A., and Coauthors, 2016: Status of high-latitude precipitation estimates from observations and reanalyses, J. Geophys. Res. Atmos., 121, 4468-4486, doi:10.1002/2015JD024546.

Bharti, V., and C. Singh, 2015: Evaluation of error in TRMM 3B42V7 precipitation estimates over the Himalayan region. J. Geophys. Res. Atmos., 120, 12458-12473, doi:https://doi.org/10.1002/2015JD023779.

Bosilovich, M. G., J. Chen, F. R. Robertson, and R. F. Adler, 2008: Evaluation of global precipitation in reanalyses. J. Appl. Meteor. Climatol., 47, 2279-2299.

Brown, P. J., R. S. Bradley, and F. T. Keimig, 2010: Changes in Extreme Climate Indices for Northeastern United States, 1870-2005. J. Climate, 23, 6555-6572.

Bukovsky, M. S. and D. J. Karoly, 2007: A Brief Evaluation of Precipitation from the North American Regional Reanalysis. J. Hydrometeor., 8, 837-846, doi:https://doi.org/10.1175/JHM595.1.

Chen, S., and Coauthors, 2013: Evaluation of the successive V6 and V7 TRMM Multisatellite Precipitation Analysis over the continental United States. Water Resour. Res., 49, 8174-8186, doi:10.1002/2012WR012795.

Contractor, S., L. V. Alexander, M. G. Donat, and N. Herold, 2015: How well do gridded datasets of observed daily precipitation compare over Australia? Adv. Meteorol., 2015, doi: $10.1155 / 2015 / 325718$. 
Daly, C., R. P. Neilson, and D. L. Phillips, 1994: A statistical-topographic model for mapping climatological precipitation over mountainous terrain. J. Appl. Meteor., 33, $140-158$.

Daly, C., 2006: Guidelines for assessing the suitability of spatial climate data sets. Int. J. Climatol., 26, 707-721.

Donat, M. G., L. V. Alexander, H. Yang, I. Durre, R. Vose, and J. Caesar, 2013: Global Land-Based Datasets for Monitoring Climate Extremes. Bull. of the Amer. Met. Soc., 94, 997-1006.

Dettinger, M. D., F. M. Ralph, T. Das, P. J. Neiman, and D. Cayan, 2011: Atmospheric rivers, floods, and the water resources of California. Water, 3, 455-478, doi:10.3390/w3020445.

Donat, M. G., A. L. Lowry, L. V. Alexander, P. A. O'Gorman, and N. Maher, 2016: More extreme precipitation in the world's dry and wet regions, Nat. Clim. Change, doi: $10.1038 /$ nclimate2941.

Durre, I., M. J. Menne, B. E. Gleason, T. G. Houston, and R. S. Vose, 2010: Robust automated quality control of daily surface observations. J. Appl. Meteor.

Climatol., 49, 1615-1633.

Easterling, D. R., and Coauthors, 2017: Precipitation change in the United States. In: Climate Science Special Report: Fourth National Climate Assessment, Volume I [Wuebbles, D.J., D.W. Fahey, K.A. Hibbard, D.J. Dokken, B.C. Stewart, and T.K. Maycock (eds.)]. U.S. Global Change Research Program, Washington, DC, USA, pp. 207-230, doi:10.7930/J0H993CC.

Ebert, E., J. Janowiak, and C. Kidd, 2007: Comparison of near real time precipitation estimates from satellite observations and numerical models, Bull. Am. Meteorol. Soc., 88, 47-64.

Frich, P., L. V. Alexander, P. Della-Marta, B. Gleason, M. Haylock, A. M. G. K. Tank, and T. Peterson, 2002: Observed coherent changes in climatic extremes during the second half of the twentieth century. Clim Res, 19, 193-212.

Gao, Y., J. Jian Lu, R. Leung, Q. Yang, S. Hagos, and Y. Qian, 2015: Dynamical and thermodynamical modulations on future changes of landfalling atmospheric rivers over western North America, Geophys. Res. Lett., 42, 7179-7186, doi:10.1002/2015GL065435.

Gelaro, R., and Coauthors, 2017: The Modern-Era Retrospective Analysis for Research and Applications, version 2 (MERRA-2). J. Climate, 30, 5419-5454, doi:https://doi.org/10.1175/JCLI-D-16-0758.1. 
Gleason, K. L., J. H. Lawrimore, D. H. Levinson, and T. R. Karl, 2008: A Revised U.S. Climate Extremes Index. J. Climate, 21, 2124-2137.

Gochis, D and Coauthors, 2015: The great Colorado flood 2013. Bull. Amer. Meteor. Soc., 96, 1461-1487.

Guan, B., N. P. Molotch, D. E. Waliser, E. J. Fetzer, and P. J. Neiman, 2010: Extreme snowfall events linked to atmospheric rivers and surface air temperature via satellite measurements. Geophys. Res. Lett., 37, L20401, doi:20410.21029/22010GL044696.

Guan, B., N. P. Molotch, D. E. Waliser, E. J. Fetzer, and P. J. Neiman, 2013: The 2010/2011 snow season in California's Sierra Nevada: Role of atmospheric rivers and modes of large-scale variability. Water Resources Research, 49, 6731-6743.

Griffiths, M. L., and R. S. Bradley, 2007: Variations of Twentieth-Century Temperature and Precipitation Extreme Indicators in the Northeast United States. J Climate, 20, 54015417.

Guirguis, K. J., and R. Avissar, 2008: A precipitation climatology and dataset intercomparison for the western United States. J. Hydrometeor., 9, 825-841.

Hanson C. E., and Coauthors, 2007: Modelling the impact of climate extremes: an overview of the MICE project. Clim. Change, 81, 163-177.

Hartmann, D. L., and Coauthors, 2013: Observations: Atmosphere and Surface. In: Climate Change 2013: The Physical Science Basis. Contribution of Working Group I to the Fifth Assessment Report of the Intergovernmental Panel on Climate Change [Stocker, T. F., D. Qin, G. K. Plattner, M. Tignor, S. K. Allen, J. Boschung, A. Nauels, Y. Xia, V. Bex and P. M. Midgley (eds.)]. Cambridge University Press, Cambridge, United Kingdom and New York, NY, USA.

Herold, N., A. Behrangi, and L. V. Alexander, 2017: Large uncertainties in observed daily precipitation extremes over land, J. Geophys. Res. Atmos., 122, 668-681, doi:10.1002/2016JD025842.

Hou, A. Y., and Coauthors, 2014: The Global Precipitation Measurement mission. Bull. Amer. Meteor. Soc., 95, 701-722, doi:https://doi.org/10.1175/BAMS-D-13-00164.1.

Huffman, G. J., and Coauthors, 2007: The TRMM Multisatellite Precipitation Analysis (TMPA): Quasi-global, multiyear, combined-sensor precipitation estimates at fine scales. J. Hydrometeor., 8, 38-55. 
Huffman, G. J., R. F. Adler, D. T. Bolvin, and G. Gu, 2010: The TRMM Multisatellite Precipitation Analysis (TMPA). Satellite Applications for Surface Hydrology, F. Hossain and M. Gebremichael, Eds., Springer, 3-22.

Huffman, G. J., and D. T. Bolvin, 2015: TRMM and other data precipitation data set documentation. NASA TRMM Doc., 44 pp. [Available online at http://pmm.nasa.gov/sites/default/files/imce/3B42_3B43 doc_V7.pdf.]

Huffman, G. J., and Coauthors, 2017: NASA Global Precipitation Measurement (GPM) Integrated Multi-satellite Retrievals for GPM (IMERG). Algorithm Theoretical Basis Doc., version 4.6, NASA, 32 pp. [Available online at https://pmm.nasa.gov/sites/default/files/document_files/IMERG_ATBD_V4.6.pdf.]

Janssen, E., D. J. Wuebbles, K. E. Kunkel, S. C. Olsen, and A. Goodman, 2014:

Observational- and model-based trends and projections of extreme precipitation over the contiguous United States. Earth's Future, 2, 99-113.

Janssen, E., R. L. Sriver, D. J. Wuebbles, and K. E. Kunkel, 2016: Seasonal and regional variations in extreme precipitation event frequency using CMIP5. Geophysical Research Letters, 43, 5385-5393. doi:http://dx.doi.org/10.1002/2016GL069151.

Kang, I. S., T. W. Kim, and K. J. Li, 1997: A spatial data mining method by Delaunay triangulation. Proc. $5^{\text {th }}$ ACM International Workshop on Advances in Geographic Information Systems. ACM Press, 35-39.

Karl, T. R., R. W. Knight, D. R. Easterling, and R. G. Quayle, 1995: Indices of climate change for the United States. Bullet. Amer. Meteor. Soc., 77, 279-292.

Karl, T. R., and R. W. Knight, 1998: Secular trends of precipitation amount, frequency, and intensity in the United States. Bullet. Amer. Meteor. Soc., 79, 231-241.

Kidd, C., A. Becker, G. J. Huffman, C. L. Muller, P. Joe, G. Skofronick-Jackson, and D. B. Kirschbaum, 2017: So, How Much of the Earth's Surface Is Covered by Rain Gauges?. Bull. Amer. Meteor. Soc., 98, 69-78, doi:https://doi.org/10.1175/BAMS-D-1400283.1.

Knight, D. B., and R. E. Davis, 2009: Contribution of tropical cyclones to extreme rainfall events in the southeastern United States. J. Geophys. Res., 114, D23102, doi:10.1029/2009JD012511.

Knutson, T. R., and Coauthors, 2010: Tropical cyclones and climate change. Nature Geoscience, 3, 157-163. doi:http://dx.doi.org/10.1038/ngeo779. 
Kunkel, K. E., K. Andsager, and D. R. Easterling, 1999: Long-term trends in extreme precipitation events over the conterminous United States and Canada. J. Climate, 12, 2515-2527.

Kunkel, K. E., T. R. Karl, and D. R. Easterling, 2007: A Monte Carlo assessment of uncertainties in heavy precipitation frequency variations. J. Hydrometeorology, 8, 11521160, doi:10.1175/JHM632.1.

Kunkel, K. E., D. R. Easterling, D. A. R. Kristovich, B. Gleason, L. Stoecker, and R. Smith, 2010: Recent increases in U.S. heavy precipitation associated with tropical cyclones. Geophysical Research Letters, 37, L24706, doi:http://dx.doi.org/10.1029/2010GL045164.

Kunkel, K. E., D. R. Easterling, D. R. Kristovich, B. Gleason, L. Stoecker, and R. Smith, 2012: Meteorological causes of the secular variations in observed extreme precipitation events for the conterminous United States. J. Hydrometeorology, 13, 1131-1141, doi:10.1175/JHMD-11-0108.1.

Kunkel, K. E., and Coauthors, 2013: Monitoring and understanding trends in extreme storms: State of knowledge. Bulletin of the American Meteorological Society, 94, 499514. doi:http://dx.doi.org/10.1175/BAMS-D-11-00262.1.

Lamjiri, M. A., Dettinger, M. D., Ralph, F. M., and B. Guan, 2017: Hourly storm characteristics along the US West Coast: Role of atmospheric rivers in extreme precipitation. Geophys. Res. Lett., 44, 7020-7028, doi:10.1002/2017GL074193.

Lee, D. T., and B. J. Schachter, 1980: Two algorithms for constructing a Delaunay triangulation. Int. J. Comput. Inf. Sci., 9, 219-242.

Lehmann, J., D. Coumou, and K. Frieler, 2015: Increased record-breaking precipitation events under global warming, Clim. Change, doi:10.1007/s10584-015-1434-y.

Lin, Y., K. E. Mitchell, E. Rogers, M. E. Baldwin, and G. I. DiMego, 1999: Test assimilations of the real-time, multi-sensor hourly precipitation analysis into the NCEP Eta model. Preprints, Eighth Conf. on Mesoscale Meteorology, Boulder, CO, Amer. Meteor. Soc., 341-344.

Liu, D., G. V. Nosovskiy, and O. Sourina, 2008: Effective clustering and boundary detection algorithm based on Delaunay triangulation. Pattern Recognition Letters, 29, 1261-1273, doi:http://dx.doi.org/10.1016/j.patrec.2008.01.028.

Liu, Z., D. Ostrenga, W. Teng, and S. Kempler, 2012: Tropical Rainfall Measuring Mission (TRMM) Precipitation Data and Services for Research and Applications. Bull. Amer., Meteor. Soc., 93, 1317-1325. 
Liu, Z., 2016: Comparison of Integrated Multisatellite Retrievals for GPM (IMERG) and TRMM Multisatellite Precipitation Analysis (TMPA) monthly precipitation products: Initial results. J. Hydrometeor., 17, 777-790, doi:10.1175/ JHM-D-15-0068.1.

Mahoney, K., D.L. Jackson, P. Neiman, M. Hughes, L. Darby, G. Wick, A. White, E. Sukovich, and R. Cifelli, 2016: Understanding the Role of Atmospheric Rivers in Heavy Precipitation in the Southeast United States. Mon. Wea. Rev., 144, 1617-1632, doi:https://doi.org/10.1175/MWR-D-15-0279.1.

Menne, M. J., I. Durre, B. G. Gleason, T. G. Houston, and R. S. Vose, 2012: An overview of the Global Historical Climatology Network-Daily database. J. Atmos. Oceanic Technol., 29, 897-910.

Mesinger, F., and Coauthors, 2006: North American Regional Reanalysis. Bull. Amer. Meteor. Soc., 87, 343-360.

Min, S. K., X. Zhang, F. W. Zwiers, and G. C. Hegerl, 2011: Human contribution to more-intense precipitation extremes. Nature, 470, 378-381, doi:http://dx.doi.org/10.1038/nature09763.

Min, S.-K., X. Zhang, F. Zwiers, H. Shiogama, Y.-S. Tung, and M. Wehner, 2013: Multimodel detection and attribution of extreme temperature changes. Journal of Climate, 26, 7430-7451, doi:http://dx.doi.org/10.1175/JCLI-D-12-00551.1.

Molod, A., L. Takacs, M. Suárez, and J. Bacmeister, 2015: Development of the GEOS-5 atmospheric general circulation model: Evolution from MERRA to MERRA2. Geosci. Model Dev., 8, 1339-1356, doi:https://doi.org/10.5194/gmd-8-1339-2015.

Neiman, P., F. M. Ralph, G. A. Wick, J. D. Lundquist, and M. D. Dettinger, 2008a: Meteorological Characteristics and Overland Precipitation Impacts of Atmospheric Rivers Affecting the West Coast of North America Based on Eight Years of SSM/I Satellite Observations. J. Hydrometeorol., 9, 22-47.

Neiman, P., F. M. Ralph, G. A. Wick, Y. H. Kuo, T. K. Wee, and Z. Ma, 2008b: Diagnosis of an Intense Atmospheric River Impacting the Pacific Northwest: Storm Summary and Offshore Vertical Structure Observed with COSMIC Satellite Retrievals. Mon. Wea. Rev., 136, 4398- 4420.

Pall, P., M. R. Allen, and D. A. Stone, 2007: Testing the Clausius-Clapeyron constraint on changes in extreme precipitation under $\mathrm{CO}_{2}$ warming. Climate Dyn., 28, 351-363, doi:10.1007/s00382-006-0180-2. 
Pall, P. and Coauthors, 2013: Diagnosing conditional anthropogenic contributions to heavy Colorado rainfall in September 2013. Weather and Climate Extremes, 17, 1-6, doi:http://dx.doi.org/10.1016/j.wace.2017.03.004.

Pratt, O., and B. Nelson, 2013: Precipitation contribution of tropical cyclones in the southeastern United States from 1998 to 2009 using TRMM satellite data. J. Climate, 26, $1047-1062$.

Ralph, F. M., P. J. Neiman, G. A. Wick, S. I. Gutman, M. D. Dettinger, D. R. Cayan, and A. B. White, 2006: Flooding on California's Russian River: Role of atmospheric rivers. Geophys. Res. Lett., 33, L13801, doi:13810.11029/12006GL026689.

Ralph, F. M., and M. D. Dettinger, 2011: Storms, Floods, and the Science of Atmospheric Rivers. EOS, 92, 265-266.

Ralph, F. M., and M. D. Dettinger, 2012: Historical and national perspectives on extreme West Coast precipitation associated with atmospheric rivers during December 2010. Bull. Amer. Meteor. Soc., 93, 783-790.

Reichle, R. H., C. S. Draper, Q. Liu, M. Girotto, S. P. P. Mahanama, R. D. Koster, and G. J. M. De Lannoy, 2017: Assessment of MERRA-2 land surface hydrology estimates. $J$. Climate, 30, 2937-2960, doi:https://doi.org/10.1175/JCLI-D-16-0720.1.

Rienecker, M. M., and Coauthors, 2011: MERRA: NASA's Modern-Era Retrospective Analysis for Research and Applications. J. Climate, 24, 3624-3648.

Turk, F. J., P. Arkin, E. E. Ebert, and M. R. P. Sapiano, 2008: Evaluating high-resolution precipitation products, Bull. Am. Meteorol. Soc., 89, 1911-1916.

Tan, J., W. A. Petersen, and A. Tokay, 2016: A novel approach to identify sources of errors in IMERG for GPM ground validation. J. Hydrometeor., 17, 2477-2491, doi:https://doi.org/10.1175/JHM-D-16-0079.1.

Trenberth, K. E., A. Dai, R. M. Rasmussen, and D. B. Parsons, 2003: The changing character of precipitation. Bull. Amer. Meteor. Soc., 84, 1205-1217.

U.S. Environmental Protection Agency (EPA), 2016: Climate change indicators in the United States, 2016. Fourth edition. EPA 430-R-16-004. [Available online at www.epa.gov/climate-indicators.]

Wang, S.-Y. S., L. Zhao, and R. R. Gillies, 2016: Synoptic and quantitative attributions of the extreme precipitation leading to the August 2016 Louisiana flood, Geophys. Res. Lett., 43, 805-814, doi:10.1002/2016GL071460. 
Warner, M.D., C.F. Mass, and E.P. Salathé, 2015: Changes in Winter Atmospheric Rivers along the North American West Coast in CMIP5 Climate Models. $J$. Hydrometeor., 16, 118-128, doi:https://doi.org/10.1175/JHM-D-14-0080.1.

Wehner, M. F., 2013: Very extreme seasonal precipitation in the NARCCAP ensemble: Model performance and projections. Climate Dynamics, 40, 59-80. doi:http://dx.doi.org/10.1007/s00382-012-1393-1.

Yin, H., Donat, M. G., Alexander, L. V. and Sun, Y., 2015: Multi-dataset comparison of gridded observed temperature and precipitation extremes over China. Int. J. Climatol., 35, 2809-2827, doi:10.1002/joc.4174.

Zhang, X., and Coauthors, 2011: Indices for monitoring changes in extremes based on daily temperature and precipitation data. WIREs Clim. Change, doi:10.1002/wcc.1147.

Zhang, X., H. Wan, F. W. Zwiers, G. C. Hegerl, and S.-K. Min, 2013: Attributing intensification of precipitation extremes to human influence. Geophysical Research Letters, 40, 5252-5257, doi:http://dx.doi.org/10.1002/grl.51010. 